University of Louisville

ThinkIR: The University of Louisville's Institutional Repository

Electronic Theses and Dissertations

$5-2012$

\title{
Using a statistical model to locate orthodontic underserved areas capable of supporting practices in Kentucky.
}

Wes Cardall

University of Louisville

Follow this and additional works at: https://ir.library.louisville.edu/etd

\section{Recommended Citation}

Cardall, Wes, "Using a statistical model to locate orthodontic underserved areas capable of supporting practices in Kentucky." (2012). Electronic Theses and Dissertations. Paper 207.

https://doi.org/10.18297/etd/207

This Master's Thesis is brought to you for free and open access by ThinkIR: The University of Louisville's Institutional Repository. It has been accepted for inclusion in Electronic Theses and Dissertations by an authorized administrator of ThinkIR: The University of Louisville's Institutional Repository. This title appears here courtesy of the author, who has retained all other copyrights. For more information, please contact thinkir@louisville.edu. 


\title{
USING A STATISTICAL MODEL TO LOCATE ORTHODONTIC UNDERSERVED AREAS CAPABLE OF SUPPORTING PRACTICES IN KENTUCKY
}

\author{
By Wes Cardall \\ BSc Brigham Young University, 2003 \\ DMD A.T. Still University, 2007
}

\author{
A Thesis \\ Submitted to the Faculty of the \\ Department of Orthodontics \\ University of Louisville School of Dentistry \\ In Partial Fulfillment of the Requirements \\ For the Degree of
}

Masters in Oral Biology

May 2012 
USING A STATISTICAL MODEL TO LOCATE ORTHODONTIC UNDERSERVED AREAS CAPABLE OF SUPPORTING PRACTICES IN KENTUCKY

\author{
By Wes Cardall \\ BSc Brigham Young University, 2003 \\ DMD A.T. Still University, 2007
}

A Thesis Approved on

By the following Thesis Committee

Eric Bednar, DDS, MS

Thesis Director

Sunita Chandiramani, DMD, MS

Carol Hanchette, PhD 


\section{DEDICATION}

This thesis is dedicated to my wife, who allowed me to spend countless Saturdays researching demographics and geography instead of being useful around the house. Thank you for your patience, understanding, and support during this long journey. 


\section{ACKNOWLEDGEMENTS}

I would like to thank my committee members, Dr. Eric Bednar, Dr. Sunita Chandiramani, and Dr. Carol Hanchette for the guidance and wisdom they have provided in support of this study. I would also like to thank the Southern Association of Orthodontists for the research grant they provided, which allowed me to purchase the demographic data used in this analysis. 


\section{ABSTRACT \\ USING A STATISTICAL MODEL TO LOCATE ORTHODONTIC UNDERSERVED AREAS CAPABLE OF SUPPORTING PRACTICES IN KENTUCKY}

Wes Cardall, DMD

April 27, 2012

Background: Malocclusion can affect an individual's quality of life. Unfortunately, access to orthodontic treatment is limited for many children. Access is improved when orthodontists select practice locations where their services are most needed.

Methods: A statistical model was applied to demographic and dental practice data in Kentucky to determine underserved areas that have the capacity to support additional orthodontic practices. All zip codes and practices were mapped using a geographic information system (GIS).

Results: The model identified 30 underserved zip codes with practice-supporting capability, but this number fell to zero after additional verification. Sixteen counties (13.3\%) contain areas located more than 30 miles from the nearest practice. Fifteen counties (12.5\%) contain areas located more than 50 miles from a Medicaid orthodontic provider.

Conclusions: Kentucky does not have a shortage of orthodontic practices, but certain regions could benefit from additional Medicaid providers. The statistical model, in conjunction with GIS, can assist in assessing practice site viability. 


\section{TABLE OF CONTENTS}

\section{PAGE}

ACKNOWLEDGEMENTS ..................................................

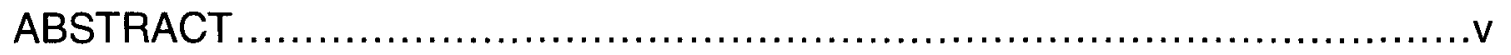

LIST OF TABLES.........................................................vii

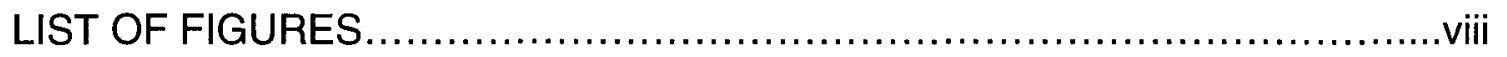
CHAPTER

I. INTRODUCTION

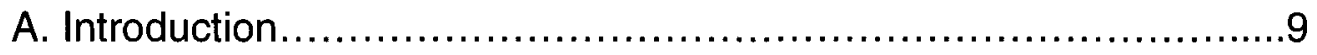

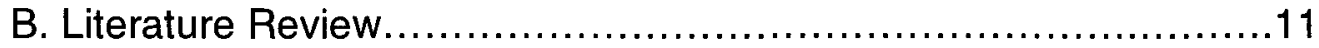

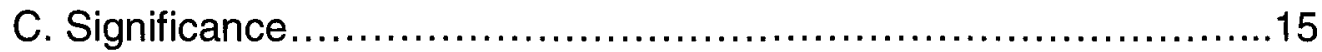
D. Purpose .............................................................
E. Hypotheses.....................................................

II. METHODS AND MATERIALS

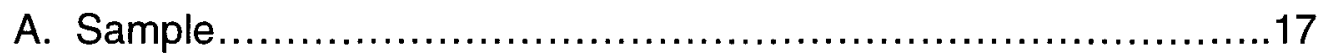
B. Inclusion/Exclusion Criteria ....................................18
C. Methods and Materials .......................................... 18
D. Statistical Analysis...............................................21

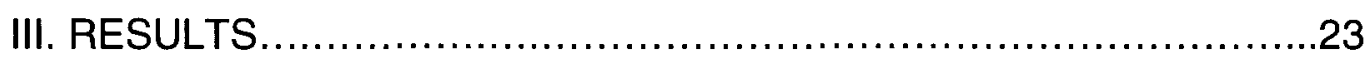

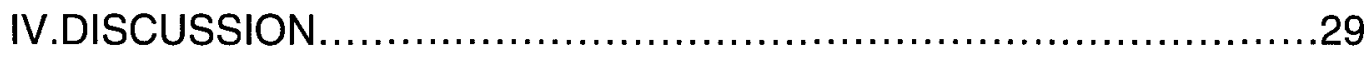

V. SUMMARY AND CONCLUSIONS ...................................33

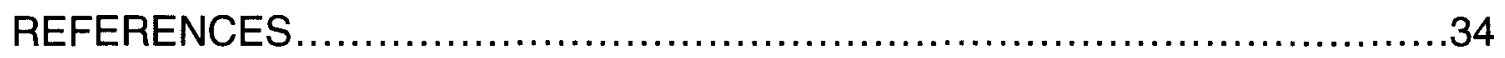

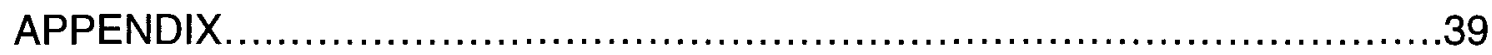

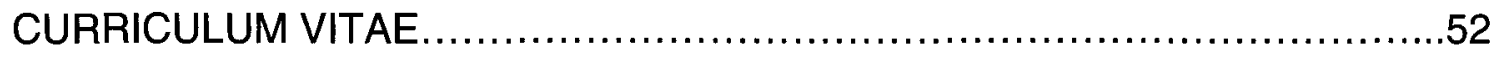




\section{LIST OF TABLES}

TABLE

PAGE

1. Unstandardized Discriminant Function Coefficients

22

2. Mean, Minimum, and Maximum Values of Kentucky Zip Codes

for Variables Used in Discriminant Analysis

23 


\section{LIST OF FIGURES}

FIGURE $\quad$ PAGE

1. 2010 Kentucky Counties and Zip Code Tabulation Areas 19

2. Number of Predicted Orthodontic Practices By Zip Code 24

3. Number of Predicted Orthodontic Practices By Zip Code, Greater Louisville Area $\quad 25$

4. Number of Predicted Orthodontic Practices By Zip Code, $\begin{array}{ll}\text { Greater Lexington Area } & 26\end{array}$

3. Areas Located $>30$ Miles from Orthodontic Practice 27

4. Areas Located $>50$ Miles from Orthodontic Medicaid Provider 28 


\section{CHAPTER I \\ INTRODUCTION}

\section{A. Introduction}

\section{Malocclusion Affects Quality of Life}

Malocclusion is not only a cosmetic problem for many American children, but it can also affect speech, mastication, psychological health, and overall oralhealth related quality of life ${ }^{1-9}$. The psychosocial impact of an individual's perception of his or her smile as unattractive can lead to decreased confidence and self-esteem ${ }^{5,6}$. Malocclusion can also lead to functional problems related to chewing, speaking, and even breathing-making these actions more difficult, albeit not impossible. Additionally, certain malocclusions may result in trauma to the oral tissue, including stripping of the gingiva and periodontal defects ${ }^{7}$.

\section{Access to Orthodontic Treatment}

Orthodontics can correct malocclusion and provide significant improvements in oral-health related quality of life, but access to orthodontic care is limited for some populations. Some children lack access to treatment because of geographic barriers, as they may live in rural areas located a considerable distance from the nearest orthodontic practice; other children may have transportation issues due to parents who are unable to take time out of work each month for appointments. Economic barriers are another major impediment 
to treatment, as many families lack funds necessary to secure care ${ }^{10,11}$. Disadvantaged children who qualify for Medicaid may receive Medicaidsponsored orthodontic care; however, many orthodontists do not participate in the Medicaid program, and thus parents must sometimes drive long distances to locate a Medicaid provider $^{12}$. Programs such as Smiles Change Lives $₫$ and Smile For a Lifetime ${ }^{\mathrm{TM}}$ are also available to help underprivileged children receive treatment, but limited funding and the difficulty of locating a nearby participating orthodontist leave many children without care ${ }^{13}$.

Studies have reported that certain populations are generally less likely to receive orthodontic treatment than others; such disparities have been linked to gender, ethnicity, and socioeconomic status. For example, male children have been reported to be less likely than females to obtain orthodontic treatment. Similarly, Black and Hispanic children have been reported to have lower odds of receiving orthodontic treatment than White children-although among adults, these ethnic and racial disparities may disappear after adjusting for other covariates $^{14}$. Children from low-income families, children with no insurance, and children eligible for Medicaid are also less likely to have initiated orthodontic treatment than children with private insurance $e^{10,15-18}$.

\section{Establishing a Practice in an Underserved Area: A Win-Win Situation}

Access to orthodontic care is improved when orthodontists select practice locations where their services are most needed-benefitting both patients and orthodontists. However, for orthodontists to set up practices in underserved areas, they must first know where these areas are, and subsequently determine 
whether these areas will be able to financially support their practice and be profitable. In essence, improving geographic access to care and promoting successful orthodontic start-up practices are two versions of the same thing. Underserved areas, by definition, have little competition, and could be financially rewarding for orthodontists while also increasing access to care for the underserved population. For the orthodontist, the selection of a practice-location site may be the most important business decision, greatly contributing to the

success or failure of a start-up venture ${ }^{19-21}$. The key to a good practice location is the identification of an area of need, so the orthodontist may use his or her skills where services will be sought. A poor choice could bring years of unnecessary economic hardship and even bankruptcy for the orthodontist. For patients, a new orthodontic practice location in a previously underserved community can be a significant benefit, allowing some who otherwise could not receive treatment to be served-especially if the new practice participates in the state's Medicaid program or a private charitable program. A new practice may also help patients and their parents avoid a potentially long and inconvenient car ride to the nearest provider.

\section{B. Literature Review}

\section{Identifying Underserved Areas for Practice Sites}

To help orthodontists select practice locations in relatively underserved areas, demographic variables considered favorable to a new practice site have been identified, and statistical and mathematical models have been proposed. These models have progressively become more sophisticated over the last thirty 
years. In 1980, Gottlieb proposed a mathematical formula which could be used to estimate how many patients an orthodontist could plan on treating in one year in any given area, based on local demographics ${ }^{22}$. This formula relies mainly on orthodontist-to-child ratios, specifically children between 7-17 years old. Other studies have produced lists of variables considered important for an area to be able to support an orthodontic practice ${ }^{23,24}$. Paul suggested that practitioners apply a site selection model which was originally developed for a general service firm, and which utilizes both objective and subjective criteria, to practice location ${ }^{20}$. Recently, Solomon and Ceen proposed a statistical model to help orthodontists determine whether an area has the typical characteristics associated with an orthodontic practice in the United States ${ }^{25}$. Their model is based on national demographic data and uses zip codes as the unit of analysis. Solomon and Ceen determined seven demographic variables which could best predict, using discriminant analysis, whether a zip code contains an orthodontic practice. They found that their model was accurate $90.3 \%$ of the time in predicting group membership.

As more orthodontists utilize objective demographic analyses in practice site location, underserved areas are likely to benefit. Recently, due to the economic recession that began in late 2007 , more practitioners have been postponing retirement, thus creating an environment where fewer practice opportunities are available for graduating residents ${ }^{26}$. In addition, more orthodontists are graduating each year as a result of an increase in the number of accredited orthodontic residency programs nationwide ${ }^{27,28}$. Another factor 
influencing the orthodontics profession includes an increase in the number of general dentists providing orthodontic treatment with clear aligners, thus decreasing the number of referrals that were received by orthodontists in past years $^{29,30}$. Lastly, a gradual decrease in the U.S. birth rate over the last 20 years has resulted in a decreased number of teenagers available for orthodontic treatment ${ }^{29}$. As a result, competition among orthodontists has increased, and more orthodontic residents are considering employment opportunities outside of their geographic preferences and are looking at objective demographic analyses in deciding where to practice ${ }^{19,25}$. As competition among orthodontists in metropolitan and suburban areas increases, orthodontists will likely look toward more underserved areas to practice, thus improving access to care for many communities located outside of metropolitan areas.

Research regarding practice location decision-making among dental professionals has a long history, and has become increasingly complex and objective. Orthodontists have not always used objective analyses in their practice location decisions. In the 1970s, dental students were characterized as irrational in their practice location decision-making, choosing often to locate in the town or community where they grew $u^{31}, 32$. In the 1980 s, objective analyses of demographics began to be utilized as an adjunct tool in location choice, although most of these analyses focused on simple orthodontist-to-population ratios ${ }^{22}$. In the 1990s, many authors advocated the need for more formal practice location planning tools and suggested using geographic information system technology and statistical models ${ }^{20,21}$. Today, some demographers use algorithms of data to 
divide populations into different lifestyle "clusters" in order to provide practitioners with a better understanding of how a practice in a given area will be utilized by its residents ${ }^{33}$. As more sophisticated demographic tools and models are at the disposal of practitioners, more uniform distribution of orthodontists among populations is possible, benefiting both patients and practitioners.

\section{Limitations of Statistical Models}

Using a statistical model to locate a practice site has inherent limitations. Models are based on current demographic estimates, which are subject to error. Another limitation involves varying utilization rates of orthodontic services by area, which may be due to various cultural factors, presence of third party insurance programs, and other unknown variables. Solomon and Ceen state that the premise of their statistical model is that orthodontists as a group generally achieve financial success, thus inferring that most orthodontists chose locations with favorable characteristics. As a result, their model assumes that current practice location characteristics can be used to suggest potential areas for new locations.

\section{Geographic Information Systems}

In order to have real practical value, results of a statistical model must be verified by entering the data into a geographic information system so that areas surrounding a location of interest may also be analyzed. For example, a model could identify a particular zip code as underserved, yet the possibility exists that the population simply travels to a nearby adjacent zip code to receive their care.

Geographic information systems technology allows analysis of geo-spatial 
relations to determine whether an area is truly underserviced. The mapping capability allows visualization of data in ways that may reveal new relationships and trends that might not be evident in other presentation formats, and the software also provides the ability to create presentation-quality maps. No previous studies have used a geographic information system to assess the viability of model-identified orthodontic practice sites.

The potential of geographic information systems to improve dental provider distribution has been recognized since the mid-1990s ${ }^{21}$. In addition to aiding practitioners in finding optimal practice sites, GIS has been used to gauge accessibility of services to the public, locate dental provider shortage areas in various states and countries, and identify future manpower needs ${ }^{11,34-38}$.

\section{Significance}

Uneven distribution of providers among a population can have negative consequences for both the providers and the population. In order to encourage providers to establish practices in underserved areas, providers must first become aware that such areas exist; additionally, they must obtain reasonable assurance that such areas have enough demand to adequately support their practice. By using a statistical model to identify underserved areas that can support their practices, practitioners have an objective gauge to assess the likelihood of success in any given area. Once an area is identified as truly underserviced, it can then be recommended for consideration by practitioners looking for a practice site with favorable demographics. 


\section{Purpose}

The goal of this study is to apply the statistical model developed by Solomon and Ceen to Kentucky zip codes, in an attempt to locate underserved areas conducive to additional orthodontic practice sites and assess the utility of using a predictive statistical model based on zip codes. A geographic information system will be used to verify whether a model-identified "underserviced" zip code is truly underserviced. Orthodontic Medicaid providers will also be entered into the geographic information system to identify regional disparities and locate areas which could benefit from additional providers.

\section{E. Hypothesis}

The null hypotheses of this study are as follows:

1. Kentucky will not have any underserved areas identified by the model.

2. After analysis with GIS, any underserved areas will turn out to be adequately serviced.

3. Kentucky will not have any Medicaid orthodontic provider shortage areas. 


\section{CHAPTER II \\ METHODS AND MATERIALS}

\section{A. Sample}

To locate orthodontic underserved areas and assess their capacity to support practices, it was necessary to secure accurate demographic data and dental and orthodontic practice data in the state of Kentucky. Estimates of 2011 demographic data for Kentucky at the zip code level were obtained from Geolytics. Geolytics is an industry leader in producing quality demographic data. Their estimates of population, income, and housing are derived from a complex modeling system based on annual and decennial US Census Data, actuarial tables, and US Post Office records of emigration and immigration. Estimates are verified for accuracy by applying controls, such as checking against county level data provided annually by the Census Bureau and other federal agencies. The demographic indicators relevant to this study include: population, percent of population without high school diploma, percent of population with college degree, median housing value, median household income, and percent of population under 18. All variables are estimated to be accurate as of 2011 , except for median housing value which is estimated to be accurate as of 2010 .

Practice locations of all dentists and orthodontists in the state of Kentucky were obtained from American Medical Information, a division of infoUSA. These 
data are meticulously maintained and updated once a month for additions or deletions. Addresses and telephone numbers are also verified once or twice a year by phone. These data include the specialty status of the dentist, but do not differentiate between primary and satellite offices. Thus, the analysis in this study is based on orthodontic practices, not orthodontists. The data are estimated to be accurate as of December 2010.

\section{B. Inclusion/Exclusion criteria}

Only zip codes fully contained within the state of Kentucky were included in this study. Because zip codes can traverse state boundaries, many zip codes that are partially contained within Kentucky were excluded. Similarly, only dental and orthodontic practices within Kentucky were included, notwithstanding many zip code areas near the state border are serviced by orthodontists in neighboring states.

\section{Methods and Materials}

After data were obtained, dental and orthodontic practice addresses were geocoded and placed on a World Street Map basemap using a geographic information system (ArcGIS 9.3, Esri Inc.). 2010 Census TIGER/line shapefiles (U.S. Census Bureau) of Kentucky counties and zip code tabulation areas (ZCTAs) were then layered on the basemap. ZCTAs are statistical geographic entities produced by the U.S. Census Bureau to overcome the difficulties in precisely defining the land area covered by a zip code. Because zip codes aren't required to be polygons and are difficult to map, ZCTAs were developed to represent the most frequent zip code in any given area and are built by 
aggregating census blocks. 2010 Kentucky counties and ZCTAs are shown in the following:

Figure 1: 2010 Kentucky Counties and Zip Code Tabulation Areas

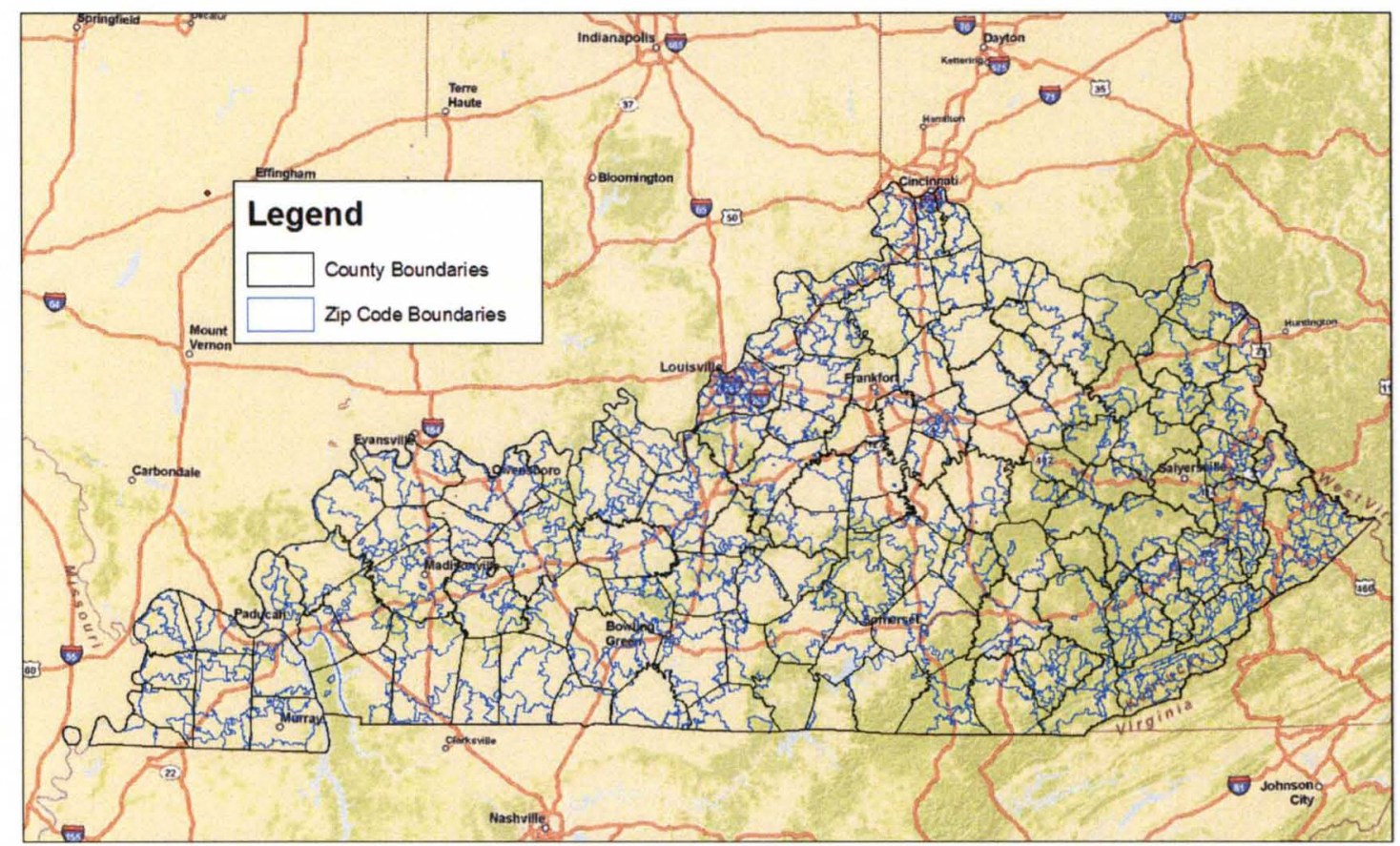

Demographic data were sorted and grouped to assemble the categories necessary to apply discriminant analysis, according to the model developed by Solomon and Ceen. In this study, discriminant analysis is used to determine whether each zip code has the characteristics associated with a typical orthodontic practice in the United States.

After classifying each Kentucky zip code by discriminant analysis, the data were joined to the zip code tabulation areas in ArcGIS. The actual presence or absence of an orthodontic practice in each zip code was then compared against the result of the predictive model. Zip codes which were predicted to have an 
orthodontic practice yet currently lack a practice ("model-identified underserved zip codes") were analyzed to see whether a nearby adjacent zip code is servicing the zip code or whether the zip code area is truly underserved. Model-identified underserved zip codes lacking an orthodontic practice in an adjacent zip code were considered truly underserved. Model-identified underserved zip codes which are located adjacent to a zip code area containing an orthodontic practice were not considered underserved, although this does not mean the zip code could not support an additional practice. The mapping capability of a geographic information system helps determine whether a model-identified underserved zip code is truly underserved, or whether its population has access to care in a nearby adjacent zip code.

As a means of verification of the accuracy of the infoUSA database, the membership directory of the American Association of Orthodontists (AAO) was used to confirm the absence of orthodontic practices in areas identified by the model as underserved.

Thirty-mile buffers were placed around each orthodontic practice in order to visualize which portions of Kentucky do not have an orthodontic practice located within thirty miles. This function was accomplished using the ArcGIS buffer tool, which creates zones of equidistance around input features in order to visualize proximity.

A listing of orthodontists in Kentucky which accept Medicaid was obtained from the Kentucky Medical Management Information System. These providers' addresses were geocoded and layered on the Kentucky map. Fifty-mile buffers 
were placed around each Medicaid provider's practice to allow visualization of areas located more than fifty miles from the nearest Medicaid orthodontic provider.

\section{Statistical analysis}

Discriminant analysis is a regression-based statistical technique used in determining which particular classification or group an item of data belongs to on the basis of its characteristics. In this study, discriminant analysis was used to classify each Kentucky zip code into one of the following groups, based on its demographic characteristics: no orthodontic practice, one orthodontic practice, and two or more orthodontic practices. In their study, Solomon and Ceen found these three groups to be statistically significant using a one-way analysis of variance (ANOVA) with a multiple range. A Group centroid of -.524 was identified for the group without an orthodontic practice; the group with one orthodontic practice had a centroid of 1.348 , and the group with two or more orthodontic practices had a centroid of 2.747. Consequently, zip codes which have a discriminant score less than 0.41 (the midpoint of the first two group centroids) were placed in the group without an orthodontic practice. Those with discriminant scores greater than 2.05 (the midpoint of the second two group centroids) were placed in the group with two or more orthodontic practices. Zip codes which have

a discriminant score greater than 0.41 and less than 2.05 were placed in the group with one orthodontic practice. 
Table 1: Unstandardized discriminant function coefficients used to calculate discriminant scores, as presented by Solomon et $\mathrm{a}^{25}$

\begin{tabular}{|l|l|}
\hline Variable & Function I \\
\hline Number of general dental practices & .1098800 \\
\hline Population (square root of) & .00968413 \\
\hline Percent of population without high school diploma & -.9717734 \\
\hline Percent of population with college degree & 1.0845764 \\
\hline Median housing value & .0000023 \\
\hline Median household income & .0000089 \\
\hline Percent of population under 18 & -1.1681554 \\
\hline (Constant) & -1.0952684 \\
\hline
\end{tabular}




\section{CHAPTER III}

\section{RESULTS}

A table containing the demographic variables and practice data used to derive discriminant scores for each Kentucky zip code may be found in the appendix.

The following table contains the mean, minimum, and maximum values of Kentucky zip codes for all variables used in calculating discriminant scores:

Table 2: Mean, Minimum, and Maximum Values of Kentucky Zip Codes for Variables Used in Discriminant Analysis

\begin{tabular}{|c|c|c|c|c|c|c|c|c|c|c|c|}
\hline & $\begin{array}{l}\text { Number of } \\
\text { Dental } \\
\text { Practices } \\
\text { (InfouSA) }\end{array}$ & $\begin{array}{l}\text { Number of } \\
\text { Ortho } \\
\text { Practices } \\
\text { (IntousA) }\end{array}$ & $\begin{array}{l}\text { Number of } \\
\text { Ortho } \\
\text { Practices } \\
\text { (AAO) }\end{array}$ & Population & $\begin{array}{l}\text { Median } \\
\text { Household } \\
\text { Incorne }\end{array}$ & $\begin{array}{l}\% \\
\text { Population } \\
\text { Under } 18\end{array}$ & $\begin{array}{l}\% \\
\text { Population } \\
\text { Without } \\
\text { High } \\
\text { School } \\
\text { Diploma }\end{array}$ & $\begin{array}{l}\% \\
\text { Population } \\
\text { With } \\
\text { College } \\
\text { Degree }\end{array}$ & $\begin{array}{l}\text { Median } \\
\text { Housing } \\
\text { Value }\end{array}$ & $\begin{array}{l}\text { Discriminant } \\
\text { Score }\end{array}$ & $\begin{array}{l}\text { Minimum } \\
\text { Predicted } \\
\text { Number of } \\
\text { Orthodontists }\end{array}$ \\
\hline MEAN & 1.55 & 0.191 & 0.211 & 5671 & 36177 & 0.2042 & 0.3312 & 0.1490 & 43815 & -0.347 & 0.179 \\
\hline MIN & 0 & 0 & 0 & 1 & 10381 & 0 & 0 & 0 & 0 & -1.6589 & 0 \\
\hline MAX & 41 & 8 & 5 & 56855 & 111698 & 0.3141 & 0.6259 & 0.866 & 275970 & 6.2109 & 2 \\
\hline
\end{tabular}

The following is a choropleth map displaying Kentucky zip codes by the number of orthodontic practices which they should be able to support, according to the model. Existing orthodontic practices in Kentucky (as listed in the infoUSA database) are also displayed: 
Figure 2: Number of Predicted Orthodontic Practices By Zip Code

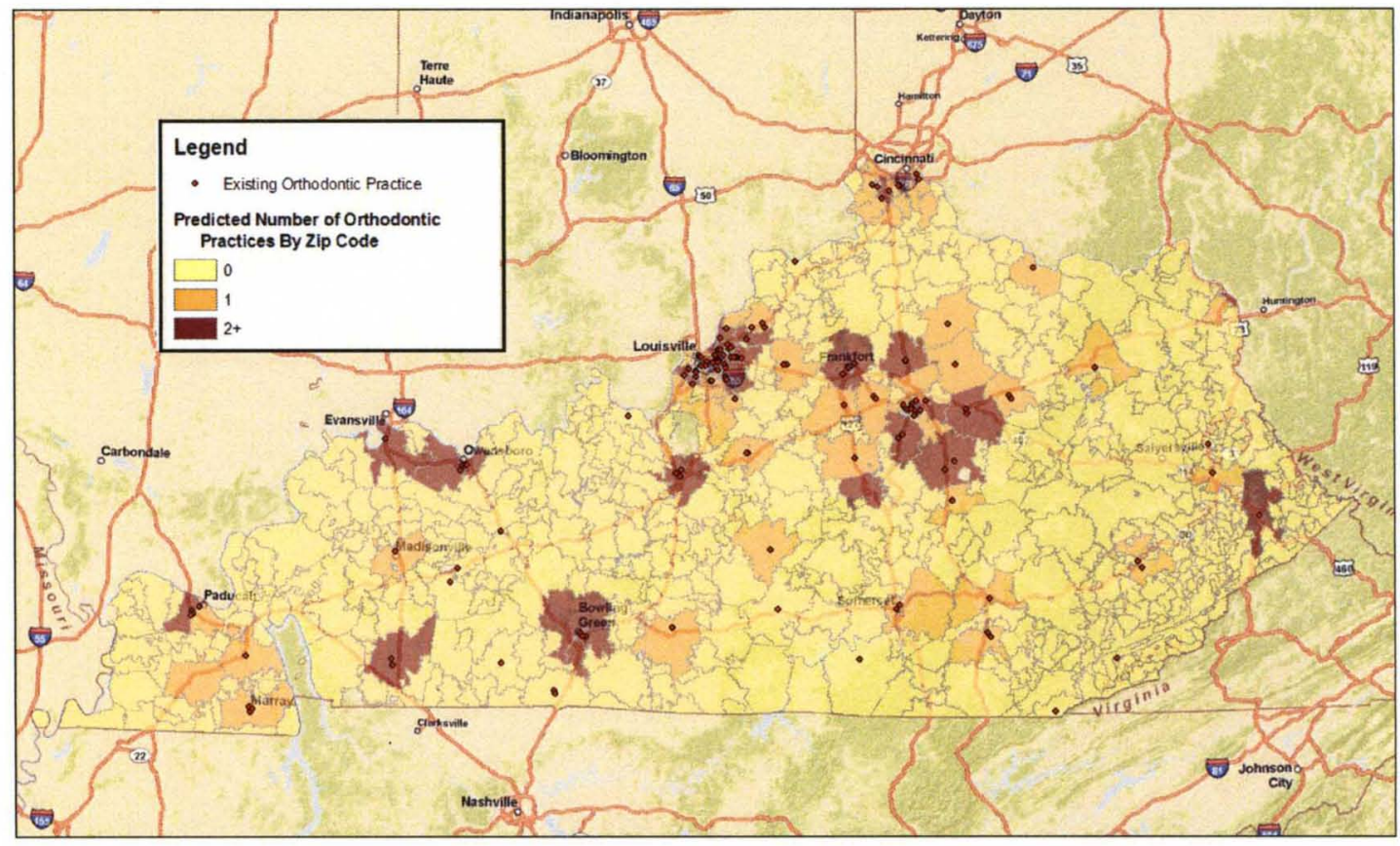

The model identified 30 out of 768 Kentucky zip codes which initially appear to not have an orthodontic practice and be capable of supporting an additional orthodontic practice; thus, the null hypothesis that Kentucky would contain no model-identified underserved areas was rejected. For verification, each of these zip codes was cross-checked with the AAO membership directory to confirm absence of an orthodontic practice. This procedure revealed that 10 of the 30 zip codes actually contain an orthodontic practice that was not listed in the original database. Using ArcMap, the remaining 20 zip codes were analyzed, and each one was found to be adjacent to a zip code containing one or more orthodontic practices. Thus, all of the model-identified underserved areas are actually adequately served, either by an orthodontic practice in an adjacent zip code or by a practice that exists in the area but was missing from the initial database. The null hypothesis that any model-identified underserved zip codes would turn out to be adequately serviced was accepted.

Of the 20 model-identified underserved zip codes, seven are contained in the Louisville metropolitan area. A choropleth map of the greater Louisville area 
displaying predicted number of orthodontic practices in each zip code as well as existing orthodontic practices is shown in the following:

Figure 3: Number of Predicted Orthodontic Practices By Zip Code, Greater Louisville Area

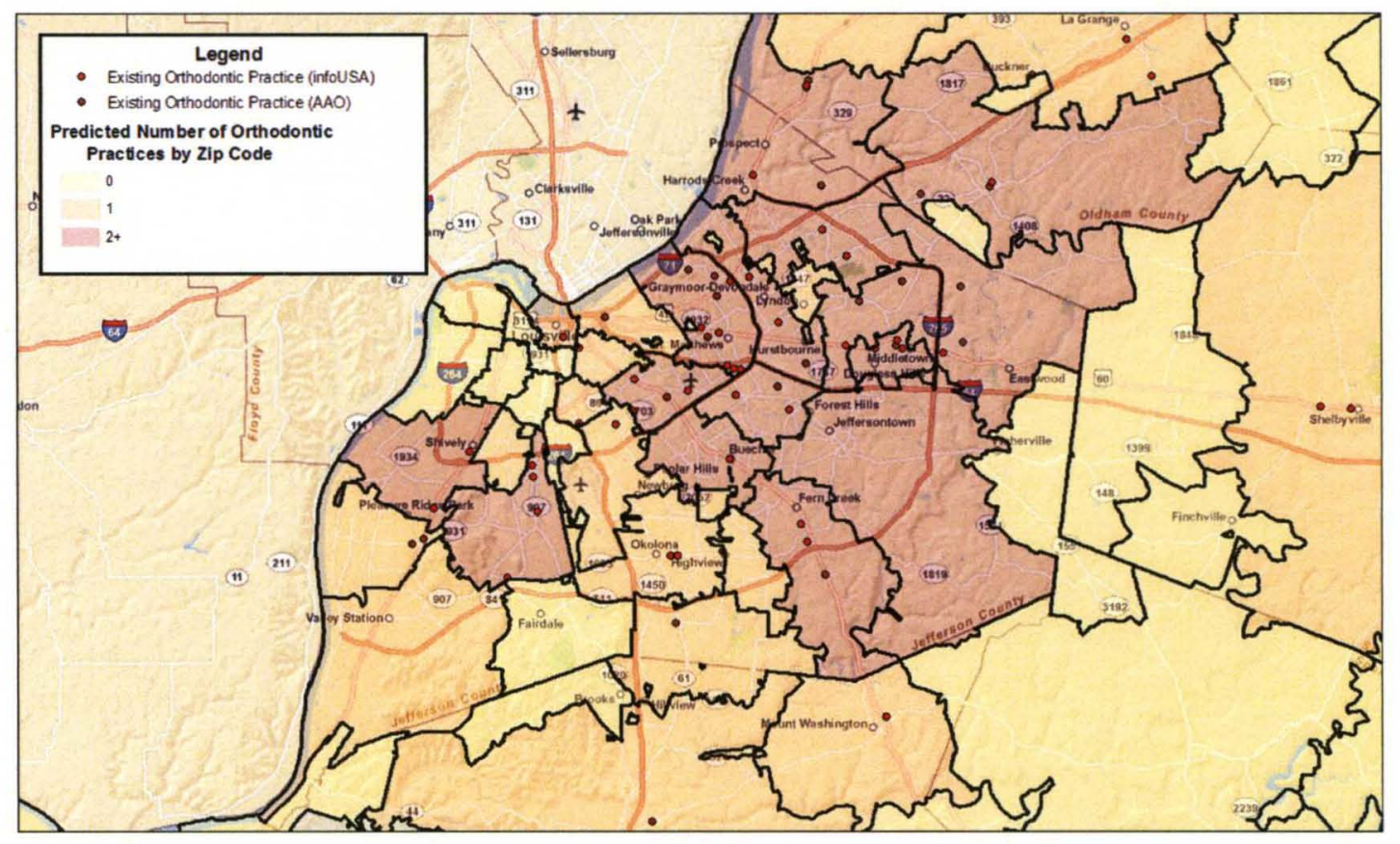

Five of the 20 model-identified underserved zip codes in Kentucky are contained in the greater Lexington area. The following map displays predicted number of orthodontic practices according to the model, as well as existing orthodontic practices in Lexington: 
Figure 4: Number of Predicted Orthodontic Practices By Zip Code, Greater Lexington Area

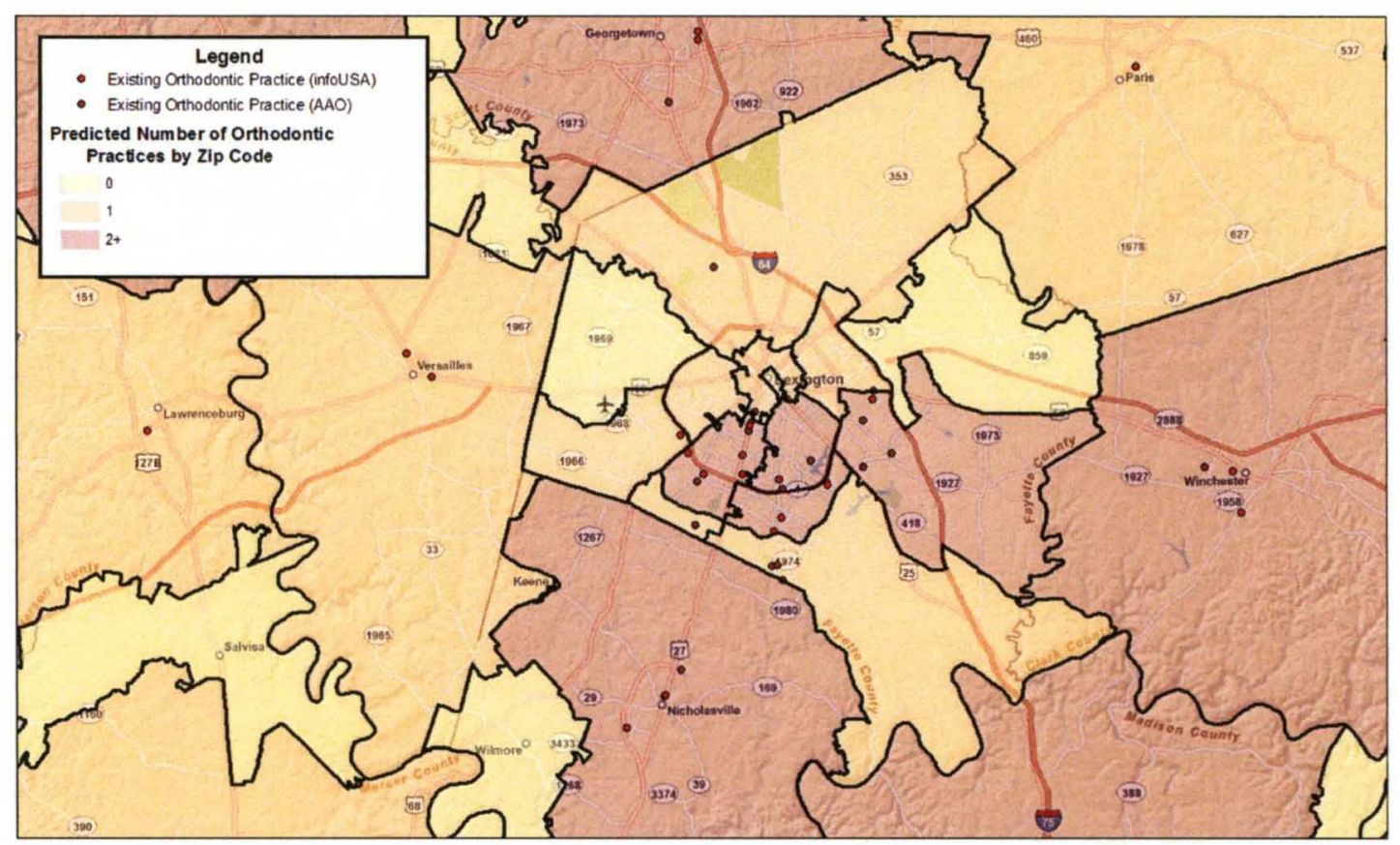

Sixteen of Kentucky's 120 counties (13.3\%) contain areas that are located more than 30 miles from the nearest orthodontic practice. However, 11 of these 16 counties border an adjacent state and would likely be served by an orthodontic practice in that bordering state rather than by a Kentucky orthodontic practice. Areas located more than 30 miles from the nearest orthodontic practice are displayed in the following map in red: 
Figure 5: Areas Located $>30$ Miles from Orthodontic Practice

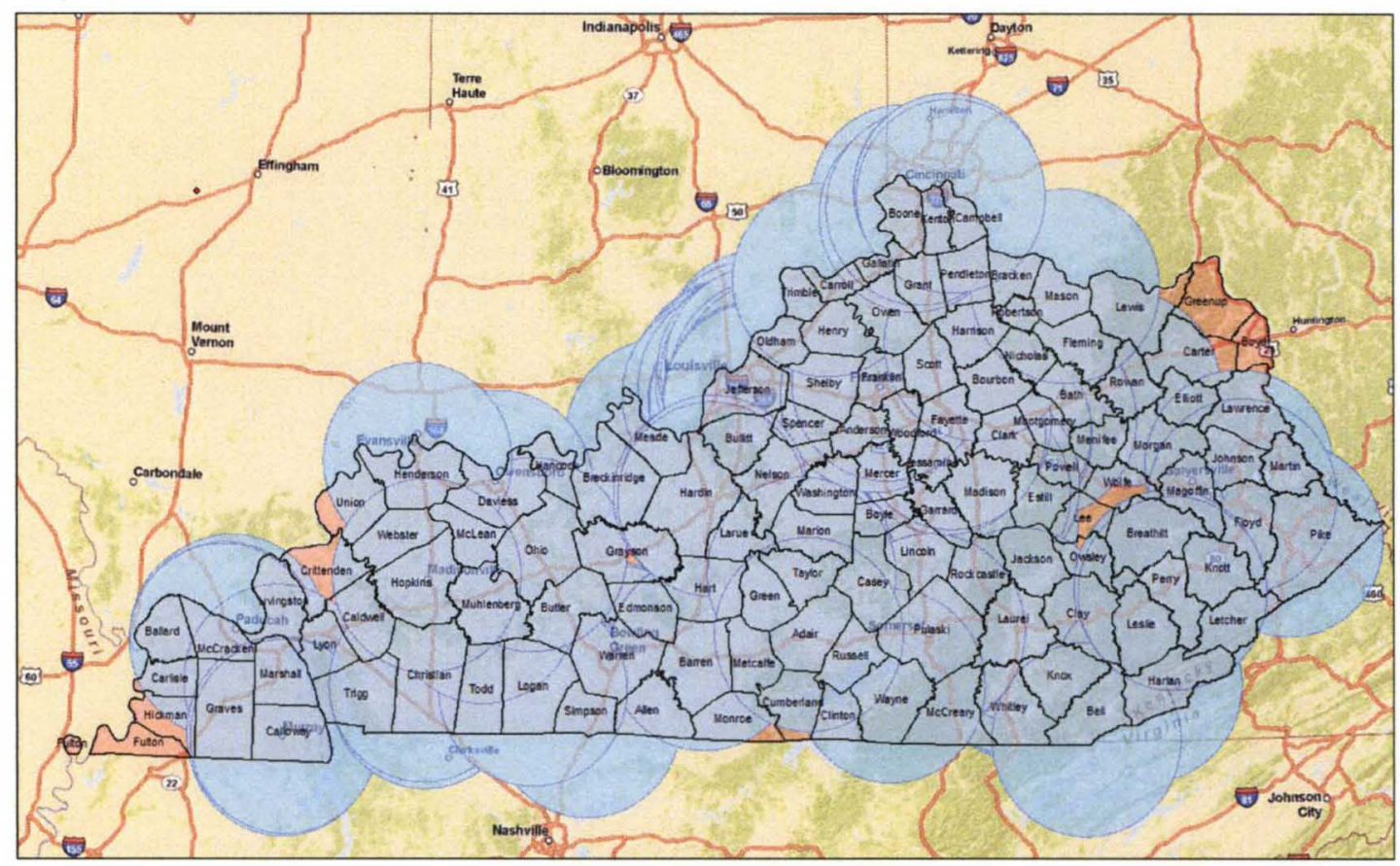

Fifteen of Kentucky's 120 counties (12.5\%) contain areas that are located greater than 50 miles from a Medicaid orthodontic provider. The null hypothesis that Kentucky would not have any Medicaid orthodontic provider shortage areas was thus rejected. Shortage areas include seven counties in southern Kentucky and six counties in eastern Kentucky, as well as portions of two counties in western Kentucky. These areas are displayed in red in the following map: 
Figure 6: Areas Located $>50$ Miles from Orthodontic Medicaid Provider

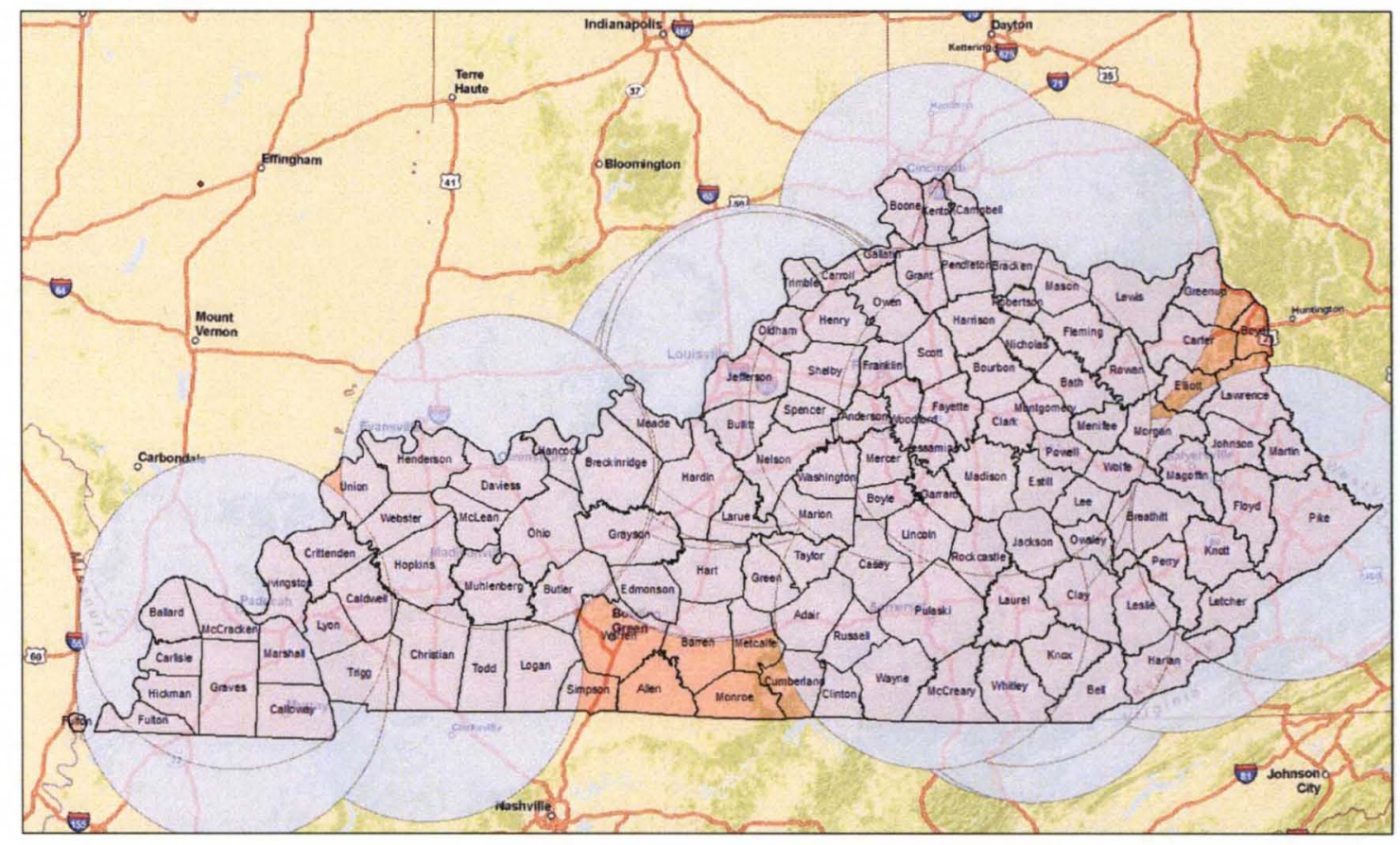




\section{CHAPTER IV}

\section{DISCUSSION}

Kentucky does not appear to have an inadequate number of orthodontic practices. According to the statistical model developed by Solomon and Ceen, thirty Kentucky zip codes were deemed to have the characteristics capable of supporting an orthodontic practice yet lacked a practice. However, after verifying the absence of practices in these zip codes with an alternate database and analyzing them using geographic information system software, all thirty zip codes were found to be adequately serviced either by an existing practice which was not listed in the original database, or by one or more practices in an adjacent zip code. Thus, according to the model, there appear to be no opportunities in Kentucky for an orthodontist to set up a practice where there is yet an unfulfilled demand and capacity to be supported. These findings do not suggest that an orthodontist will be unsuccessful by setting up a new practice, but only that current zip code tabulation areas seem to be adequately served by existing practices or by practices in adjacent zip codes. However, the twenty modelidentified underserved zip codes that currently lack a practice may still be viable practice sites.

As one may see from looking at Figure 2, providers have distributed themselves across all regions of the state where they are likely to be adequately 
supported. The geographic information system is a valuable asset in analyzing the distribution of providers and identifying potential shortage areas. In Kentucky, geographic shortage areas of orthodontic providers appear to be few. As predicted, all of the underserviced areas are rural. These results are consistent with those of many other studies that have demonstrated provider shortage areas among rural populations ${ }^{11,35-38}$. Proposed reasons for shortages in rural areas include strong financial disincentives for practitioners and a lower demand for oral health care ${ }^{39}$.

The results of this study call into question conclusions from other studies that predict upcoming shortfalls in the number of orthodontic providers, or that assume an imbalance in orthodontist distribution ${ }^{27,40}$. Perhaps due to the increase in general dentists providing orthodontics using clear aligners, or because of effects of the "new economy" born of the latest recession--or perhaps a combination-the shortfall in number of orthodontic providers necessary to treat the population has not occurred and is not expected to occur anytime in the next decade. On the contrary, recent estimates suggest that an "orthodontic recession" has arrived which may last until at least $2020^{29}$. In recent surveys, many orthodontists have reported having less work than they desire, as the number of case starts and active cases has declined in many practices ${ }^{41}$. A tendency toward professional saturation of orthodontists in the United States seems more likely than a shortage, which would be consistent with recent studies in other countries ${ }^{42}$. An imbalance in orthodontist distribution in Kentucky is not corroborated by this study, as orthodontists have established practices in all 
areas of the state where they can be adequately supported, according to the model. Some isolated geographic areas lack access to a provider within 30 miles-as demonstrated in Figure 5--but these areas are few in number and size, and because of their rural locations, they affect a small number of Kentuckians. When the maximum distance from an orthodontic provider is increased to 40 miles, all of the identified shortage areas-except for a small portion of Kentucky's westernmost county, Fulton County-disappear. Fulton County, which borders Missouri and Tennessee, is likely served by orthodontic providers in those states. Additional studies are necessary to verify whether an imbalance in orthodontic provider distribution exists in other states.

Some areas in southern Kentucky and eastern Kentucky lack an orthodontic Medicaid provider. Children in portions of seven counties in southern Kentucky must travel more than 50 miles to reach the nearest Medicaid orthodontist, as do children in parts of six counties in eastern Kentucky. Each of these regions could benefit from an additional Medicaid provider.

Previous studies have addressed why some orthodontists choose not to participate in the Medicaid program. Reasons cited by orthodontists as deterrents to participate include low fee reimbursement, high appointment failure rate, difficulty collecting from Medicaid, loss of coverage during treatment, prior authorization requirement, payment delays, difficulty getting billing questions answered, uncooperative behavior from patients, tardiness to appointments, and last-minute cancellations ${ }^{12,43,44}$. 
A limitation of this study is the inherent inaccuracy of databases due to constant change. Although the infoUSA database is verified monthly for changes and its proprietors claim to meticulously maintain it, many deletions and inaccuracies were found. By using the AAO membership directory as a crossvalidation tool, a more accurate database was assembled. However, some doctors choose to list their home address in the directory rather than a practice address, which complicates the ability to verify practice locations. Other potential verification sources, such as online search engines, white pages, and the Kentucky Dental Board directory, are also subject to inaccuracies. The online Medicaid provider directory, which was used as the basis for this study's Medicaid database, may also contain errors.

This study used zip code tabulation areas, rather than census tracts, as its geographic unit of analysis because a larger unit of analysis was needed to be able to predict whether an area could support an orthodontic practice. Zip codes generally contain larger populations than census tracts and are a larger unit of analysis. Because the typical orthodontic practice serves approximately 15,000 20,000 people, a unit of analysis that contains a relatively large population was necessary for the model to produce useful data. Census tracts are better units for geographic analysis than zip codes because they are more homogenous; however, a census tract typically only contains approximately 4000 people, which is an inadequate number to be able to predict whether an area could potentially support an orthodontic practice. 


\section{CHAPTER V \\ CONCLUSIONS}

\section{A. Summary:}

The aims of this study were to apply a statistical model to Kentucky zip codes to identify underserved areas and assess their viability using a geographic information system, as well as to identify orthodontic Medicaid shortage areas. This study found that the statistical model significantly overestimates the number of underserved areas; the model identified 30 underserved zip codes which, after analysis with a geographic information system, were all found to be adequately serviced. Sixteen Kentucky counties contain portions that are located greater than 30 miles from the nearest orthodontic practice. Fifteen Kentucky counties contain areas that lack access to a Medicaid orthodontic provider within 50 miles.

\section{B. Conclusions:}

Kentucky has very few areas that have inadequate access to an orthodontic practice. However, certain areas lack a Medicaid orthodontic provider within a reasonable distance. A statistical model can be a useful adjunct in identifying potential practice sites when used in combination with a geographic information system. 


\section{REFERENCES}

1. Ekuni D, Furuta M, Irie K, Azuma T, Tomofuji T, Murakami T, et al.

Relationship between impacts attributed to malocclusion and psychological stress in young Japanese adults. Eur J Orthod 2011.

2. English JD, Buschang PH, Throckmorton GS. Does malocclusion affect masticatory performance? Angle Orthod 2002;72(1):21-7.

3. Hassan AH, Amin Hel S. Association of orthodontic treatment needs and oral health-related quality of life in young adults. Am J Orthod Dentofacial Orthop 2010;137(1):42-7.

4. Johnson NC, Sandy JR. Tooth position and speech--is there a relationship? Angle Orthod 1999;69(4):306-10.

5. Jung MH. Evaluation of the effects of malocclusion and orthodontic treatment on self-esteem in an adolescent population. Am J Orthod Dentofacial Orthop 2010;138(2):160-6.

6. Khan M, Fida M. Assessment of psychosocial impact of dental aesthetics. J Coll Physicians Surg Pak 2008;18(9):559-64.

7. Zhang $M, M c G$ rath $C$, Hagg U. The impact of malocclusion and its treatment on quality of life: a literature review. Int J Paediatr Dent $2006 ; 16(6): 381-7$. 
8. Feu D, de Oliveira BH, de Oliveira Almeida MA, Kiyak HA, Miguel JA. Oral health-related quality of life and orthodontic treatment seeking. Am J Orthod Dentofacial Orthop 2010;138(2):152-9.

9. Olsen JA, Inglehart MR. Malocclusions and perceptions of attractiveness, intelligence, and personality, and behavioral intentions. Am J Orthod Dentofacial Orthop 2011;140(5):669-79.

10. Martin CA, McNeil DW, Crout RJ, Ngan PW, Weyant RJ, Heady HR, et al. Oral health disparities in Appalachia: orthodontic treatment need and demand. J Am Dent Assoc 2008;139(5):598-604; quiz 27.

11. Marriott A, Harding W, Devlin N, Benwell G. The delivery of orthodontic care in New Zealand. Part I: Analysis of a census of orthodontists. N Z Dent J 2001;97(429):87-92.

12. Fisher MA. North Carolina orthodontists' Medicaid provider status is associated with perception of major problems with Medicaid. J Evid Based Dent Pract 2009;9(1):47-50.

13. Litton SF. Smiles Change Lives to help in access to orthodontic care. Angle Orthod 2008;78(1):189-90.

14. Whitesides J, Pajewski NM, Bradley TG, lacopino AM, Okunseri C. Sociodemographics of adult orthodontic visits in the United States. Am J Orthod Dentofacial Orthop 2008;133(4):489 e9-14.

15. Okunseri C, Pajewski NM, McGinley EL, Hoffmann RG. Racial/ethnic disparities in self-reported pediatric orthodontic visits in the United States. J Public Health Dent 2007;67(4):217-23. 
16. Waldman HB. Who uses and who provides orthodontic services? N Y State Dent J 2007;73(1):61-2.

17. Germa A, Kaminski M, Nabet C. Impact of social and economic characteristics on orthodontic treatment among children and teenagers in France. Community Dent Oral Epidemiol 2010;38(2):171-9.

18. Huang GJ, Marston BE, del Aguila MA. Orthodontic care in an insured population in Washington: demographic factors. Am J Orthod Dentofacial Orthop 2004;125(6):741-6.

19. Bentson C. 2010 Annual Resident Survey Results. Bentson Clark Resource 2010;5(4):1-11.

20. Paul DP, 3rd. Dental practice location: some aspects of the importance of selection of place. Health Mark Q 1997;14(4):55-69.

21. Sponzo JM. Answering the 'where' questions. Dent Econ 1996;86(5):46$51,53$.

22. Gottlieb EL. Orthodontic economics. Population. J Clin Orthod $1980 ; 14(7): 490-9$.

23. Pride J. Thinking About Relocating: Some Tips on Choosing an Office Site. J Am Dent Assoc 1992;123:212-6.

24. Hochman RM. Relocating the dental office. Dent Clin North Am $1981 ; 25(4): 615-20$.

25. Solomon ES, Ceen RF. Demographic characteristics of orthodontic practice sites in the United States. Am J Orthod Dentofacial Orthop 2008;133(4 Suppl):S115-20. 
26. Bentson C. Looking Back at the Practice Valuations of 2010. Bentson Clark Resource 2011;6(1):1-9.

27. Waldman HB, Perlman SP, Schindel R. Update on the imbalanced distribution of orthodontists, 1995-2006. Am J Orthod Dentofacial Orthop 2009;135(6):704-8.

28. SurveyCenter. 2009-10 Survey of Advanced Dental Education. Chicago: American Dental Association 2010.

29. Sellke T. The State of Orthodontics. The Progressive Orthodontist; 2011. p. 18-19.

30. Roncone R. The Perfect Storm. Orthotown; 2012. p. 36-37.

31. Grantham EV, Milone CL. The fallacy of practice location decision making research. J Dent Educ 1978;42(12):666-7.

32. Survey of recent dental graduates. II. Factors related to selection of a practice location. J Am Dent Assoc 1973;87(4):904-6.

33. McDonald S. Key factors in determining a dental practice site. J Calif Dent Assoc 2001;29(4):283-8.

34. Horner MW, Mascarenhas AK. Analyzing location-based accessibility to dental services: an Ohio case study. J Public Health Dent 2007;67(2):1138.

35. Mertz EA, Grumbach K. Identifying communities with low dentist supply in California. J Public Health Dent 2001;61(3):172-7.

36. Bamford EJ, Dunne L, Taylor DS, Symon BG, Hugo GJ, Wilkinson D. Accessibility to general practitioners in rural South Australia. A case study 
using geographic information system technology. Med J Aust 1999;171(11-12):614-6.

37. Susi L, Mascarenhas AK. Using a geographical information system to map the distribution of dentists in Ohio. J Am Dent Assoc 2002;133(5):636-42.

38. Krause D, Frate DA, May WL. Demographics and distribution of dentists in Mississippi: a dental work force study. J Am Dent Assoc 2005;136(5):66877.

39. Allison RA, Manski RJ. The supply of dentists and access to care in rural Kansas. J Rural Health 2007;23(3):198-206.

40. Waldman HB. Personnel planning for the next generation of orthodontic patients. Am J Orthod Dentofacial Orthop 1996;110(5):520-6; discussion 27.

41. Keim RGea. 2011 JCO Orthodontic Practice Study. Part I: Trends. Journal of Clinical Orthodontics 2011;XLV(10):535-44.

42. Shpack N, Gordon M. [ls there a tendency for professional saturation in orthodontics in Israel?]. Refuat Hapeh Vehashinayim 2007;24(2):37-45, 71.

43. Horsley BP, Lindauer SJ, Shroff B, Tufekci E, Abubaker AO, Fowler CE, et al. Appointment keeping behavior of Medicaid vs non-Medicaid orthodontic patients. Am J Orthod Dentofacial Orthop 2007;132(1):49-53.

44. Fisher MA. North Carolina orthodontists' Medicaid provider status is associated with perceived problems with Medicaid. J Evid Based Dent Pract 2009;9(1):42-4. 


\section{APPENDIX}

\section{Column Headings, From Left to Right:}

Zip Code Tabulation Area, Number of Dental Practices (infoUSA), Number of Orthodontic

Practices (infoUSA), Population, Median Household Income, Percentage of Population Under

18, Percentage of Population Without High School Diploma, Median Housing Value,

Discriminant Score, Minimum Number of Orthodontic Practices According to Model, Number

of Orthodontic Practices (AAO)

\begin{tabular}{|c|c|c|c|c|c|c|c|c|c|c|c|}
\hline Zip & DntPr & OrtPr & Pop & HHInC & Under 18 & NoHSDip & WithColDeg & MdHVal & DiscScore & $\mathrm{MnOr}$ & AAO \\
\hline 40003 & 0 & 0 & 2021 & 58531 & 0.208312716 & 0.219476744 & 0.199854651 & 49430 & -0.26537223 & 0 & 0 \\
\hline 40004 & 9 & 2 & 28205 & 44260 & 0.235206524 & 0.181897255 & 0.225659147 & 82411 & 1.892957727 & 1 & 2 \\
\hline 40006 & 0 & 0 & 4921 & 44921 & 0.223125381 & 0.316095471 & 0.13494492 & 67889 & -0.28166997 & 0 & 0 \\
\hline 40007 & 0 & 0 & 213 & 37402 & 0.197183099 & 0.22147651 & 0.11409396 & 22834 & -0.89055623 & 0 & 0 \\
\hline 40008 & 1 & 0 & 4036 & 47221 & 0.226709613 & 0.316672883 & 0.129056322 & 62464 & -0.23943977 & 0 & 0 \\
\hline 40009 & 0 & 0 & 1368 & 36554 & 0.218567251 & 0.385606874 & 0.099892589 & 38975 & -0.84403382 & 0 & 0 \\
\hline 40010 & 0 & 0 & 323 & 79460 & 0.278637771 & 0.126984127 & 0.407407407 & 4872 & -0.21012986 & 0 & 0 \\
\hline 40011 & 1 & 0 & 2944 & 44178 & 0.221127717 & 0.264093448 & 0.125444388 & 48848 & -0.33391571 & 0 & 0 \\
\hline 40012 & 0 & 0 & 399 & 46310 & 0.210526316 & 0.419708029 & 0.072992701 & 23787 & -1.00979187 & 0 & 0 \\
\hline 40013 & 0 & 0 & 6693 & 58492 & 0.215747796 & 0.213713268 & 0.162288513 & 65226 & 0.08368693 & 0 & 0 \\
\hline 40014 & 9 & 1 & 22626 & 79460 & 0.256386458 & 0.096125239 & 0.417369129 & 130116 & 2.412766702 & 2 & 4 \\
\hline 40019 & 1 & 0 & 4095 & 40981 & 0.233699634 & 0.297297297 & 0.149024024 & 68685 & -0.2438742 & 0 & 0 \\
\hline 40020 & 0 & 0 & 29 & 60093 & 0.206896552 & 0.052631579 & 0.157894737 & 3107 & -0.62293525 & 0 & 0 \\
\hline 40022 & 0 & 0 & 898 & 78115 & 0.197104677 & 0.24600639 & 0.236421725 & 64230 & -0.17520602 & 0 & 0 \\
\hline 40023 & 2 & 0 & 3564 & 90067 & 0.221099888 & 0.146189088 & 0.309870887 & 62351 & 0.582362318 & 0 & 0 \\
\hline 40025 & 0 & 0 & 49 & 111698 & 0.12244898 & 0.025 & 0.65 & 0 & 0.504151149 & 0 & 0 \\
\hline 40026 & 1 & 0 & 6875 & 88888 & 0.257890909 & 0.057218099 & 0.514484079 & 143249 & 1.138640856 & 1 & 0 \\
\hline 40031 & 7 & 3 & 21617 & 50526 & 0.196789564 & 0.211828448 & 0.25576082 & 103480 & 1.624128916 & 1 & 1 \\
\hline 40033 & 0 & 0 & 12526 & 33487 & 0.21571132 & 0.304609929 & 0.160874704 & 72717 & 0.080128118 & 0 & 0 \\
\hline 40036 & 0 & 0 & 368 & 59742 & 0.203804348 & 0.271653543 & 0.098425197 & 12751 & -0.74397847 & 0 & 0 \\
\hline 40037 & 0 & 0 & 3055 & 42966 & 0.225859247 & 0.232363098 & 0.136161815 & 55298 & -0.39261478 & 0 & 0 \\
\hline 40040 & 0 & 0 & 511 & 49975 & 0.215264188 & 0.324637681 & 0.136231884 & 29196 & -0.78382501 & 0 & 0 \\
\hline 40041 & 0 & 0 & 250 & 39477 & 0.212 & 0.106508876 & 0.562130178 & 0 & -0.33249387 & 0 & 0 \\
\hline 40045 & 0 & 0 & 3817 & 50949 & 0.205396909 & 0.269390844 & 0.152478244 & 74463 & -0.20880715 & 0 & 0 \\
\hline 40046 & 0 & 0 & 2273 & 51278 & 0.212494501 & 0.26185835 & 0.141650422 & 27915 & -0.46226458 & 0 & 0 \\
\hline 40047 & 5 & 1 & 18972 & 56153 & 0.223329117 & 0.18028731 & 0.191300878 & 109781 & 1.309486415 & 1 & 1 \\
\hline 40048 & 0 & 0 & 28 & 58492 & 0.214285714 & 0.055555556 & 0.222222222 & 0 & -0.58694973 & 0 & 0 \\
\hline 40049 & 0 & 0 & 10 & 42966 & 0.3 & 0 & 0 & 0 & -1.03299371 & 0 & 0 \\
\hline 40050 & 0 & 0 & 1310 & 37382 & 0.203816794 & 0.34939759 & 0.186199343 & 65533 & -0.63721743 & 0 & 0 \\
\hline 40051 & 0 & 0 & 4491 & 38679 & 0.219327544 & 0.248411902 & 0.138415246 & 58480 & -0.31524622 & 0 & 0 \\
\hline 40052 & 0 & 0 & 644 & 36452 & 0.215838509 & 0.284064665 & 0.122401848 & 6636 & -0.90546822 & 0 & 0 \\
\hline 40055 & 1 & 0 & 1747 & 46820 & 0.214653692 & 0.239388795 & 0.15959253 & 45080 & -0.37113446 & 0 & 0 \\
\hline 40056 & 0 & 0 & 2252 & 73679 & 0.210035524 & 0.145806452 & 0.370322581 & 112694 & 0.293621766 & 0 & 0 \\
\hline 40057 & 0 & 0 & 3008 & 44925 & 0.214095745 & 0.261764706 & 0.123529412 & 52261 & -0.41481729 & 0 & 0 \\
\hline 40058 & 0 & 0 & 4 & 37382 & 0.25 & 0 & 0 & 0 & -1.03548919 & 0 & 0 \\
\hline 40059 & 9 & 2 & 15278 & 111500 & 0.23897107 & 0.043606424 & 0.682049197 & 275970 & 3.132168393 & 2 & 3 \\
\hline 40060 & 0 & 0 & 1291 & 38650 & 0.213787761 & 0.257918552 & 0.139140271 & 69673 & -0.59276123 & 0 & 0 \\
\hline 40062 & 0 & 0 & 292 & 36452 & 0.232876712 & 0.21875 & 0.083333333 & 29895 & -0.93106774 & 0 & 0 \\
\hline
\end{tabular}




\begin{tabular}{|c|c|c|c|c|c|c|c|c|c|c|c|}
\hline 40063 & 0 & 0 & 39 & 46876 & 0.179487179 & 0.214285714 & 0.142857143 & 0 & -0.8807407 & 0 & 0 \\
\hline 40065 & 8 & 2 & 28741 & 60041 & 0.228140983 & 0.223467509 & 0.249618521 & 118063 & 2.015150813 & 1 & 3 \\
\hline 40067 & 2 & 0 & 5931 & 74860 & 0.199291856 & 0.179222649 & 0.2871881 & 109084 & 0.69096905 & 0 & 0 \\
\hline 40068 & 0 & 0 & 2888 & 49974 & 0.197368421 & 0.178321678 & 0.237762238 & 50285 & -0.16058934 & 0 & 0 \\
\hline 40069 & 3 & 0 & 8907 & 38931 & 0.203996856 & 0.281485116 & 0.199378476 & 73218 & 0.366238522 & 0 & 0 \\
\hline 40070 & 0 & 0 & 604 & 41827 & 0.218543046 & 0.253694581 & 0.172413793 & 32980 & -0.72420143 & 0 & 0 \\
\hline 40071 & 2. & 0 & 14863 & 58866 & 0.221489605 & 0.230288365 & 0.171103045 & 107436 & 0.778178345 & 0 & 0 \\
\hline 40075 & 0 & 0 & 1330 & 48130 & 0.215037594 & 0.239733629 & 0.119866815 & 50799 & -0.55127597 & 0 & 0 \\
\hline 40076 & 0 & 0 & 2634 & 53377 & 0.205770691 & 0.229961305 & 0.168601437 & 53630 & -0.2810373 & 0 & 0 \\
\hline 40077 & 0 & 0 & 540 & 47372 & 0.207407407 & 0.08401084 & 0.279132791 & 62631 & -0.32595761 & 0 & 0 \\
\hline 40078 & 0 & 0 & 1977 & 42449 & 0.194739504 & 0.391715116 & 0.114098837 & 60122 & -0.63319186 & 0 & 0 \\
\hline 40104 & 0 & 0 & 1516 & 40477 & 0.200527704 & 0.275238095 & 0.121904762 & 40617 & -0.6342463 & 0 & 0 \\
\hline 40107 & 0 & 0 & 2206 & 48885 & 0.201269266 & 0.229605263 & 0.136184211 & 57043 & -0.38488522 & 0 & 0 \\
\hline 40108 & 2 & 0 & 10985 & 43998 & 0.208921256 & 0.224266198 & 0.20289463 & 86139 & 0.486254265 & 0 & 0 \\
\hline 40109 & 1 & 0 & 1587 & 44004 & 0.171392565 & 0.275474957 & 0.095854922 & 100534 & -0.34125007 & 0 & 0 \\
\hline 40110 & 0 & 0 & 43 & 58934 & 0.186046512 & 0.133333333 & 0.1 & 0 & -0.74588214 & 0 & 0 \\
\hline 40111 & 0 & 0 & 1357 & 32783 & 0.214443626 & 0.294307197 & 0.111707841 & 37791 & -0.77540359 & 0 & 0 \\
\hline 40115 & 0 & 0 & 664 & 27058 & 0.225903614 & 0.366742597 & 0.111617312 & 28925 & -1.03783175 & 0 & 0 \\
\hline 40117 & 0 & 0 & 2488 & 41755 & 0.22266881 & 0.265885256 & 0.145589143 & 30111 & -0.53216271 & 0 & 0 \\
\hline 40118 & 1 & 0 & 9475 & 43065 & 0.223007916 & 0.293745051 & 0.109263658 & 83267 & 0.103981902 & 0 & 0 \\
\hline 40119 & 0 & 0 & 2042 & 38617 & 0.184622919 & 0.316757493 & 0.142370572 & 38633 & -0.59436757 & 0 & 0 \\
\hline 40121 & 0 & 0 & 10031 & 42589 & 0.309640116 & 0.071982681 & 0.321847375 & 58636 & 0.305649178 & 0 & 0 \\
\hline 40140 & 0 & 0 & 1113 & 29844 & 0.222821204 & 0.347184987 & 0.103217158 & 23192 & -0.93918745 & 0 & 0 \\
\hline 40142 & 0 & 0 & 3015 & 45922 & 0.216915423 & 0.2765 & 0.116 & 42331 & -0.45394757 & 0 & 0 \\
\hline 40143 & 2 & 0 & 4928 & 40320 & 0.207386364 & 0.285164347 & 0.119040569 & 46930 & -0.12015566 & 0 & 0 \\
\hline 40144 & 0 & 0 & 3190 & 31437 & 0.209717868 & 0.285975331 & 0.122887163 & 34853 & -0.5781722 & 0 & 0 \\
\hline 40145 & 0 & 0 & 964 & 50792 & 0.237551867 & 0.422222222 & 0.1 & 27741 & -0.85832078 & 0 & 0 \\
\hline 40146 & 0 & 0 & 3425 & 30339 & 0.218686131 & 0.293525809 & 0.109798775 & 54768 & -0.55436921 & 0 & 0 \\
\hline 40150 & 1 & 0 & 3876 & 46377 & 0.191950464 & 0.329862402 & 0.107846783 & 80025 & -0.21406094 & 0 & 0 \\
\hline 40152 & 0 & 0 & 517 & 41921 & 0.189555126 & 0.293010753 & 0.112903226 & 23340 & -0.83220258 & 0 & 0 \\
\hline 40155 & 0 & 0 & 903 & 37715 & 0.194905869 & 0.290529695 & 0.101123596 & 59590 & -0.73206821 & 0 & 0 \\
\hline 40157 & 0 & 0 & 936 & 31884 & 0.204059829 & 0.264240506 & 0.056962025 & 29004 & -0.88209407 & 0 & 0 \\
\hline 40160 & 8 & 0 & 21692 & 44116 & 0.235432417 & 0.156510086 & 0.199605022 & 84081 & 1.58209022 & 1 & 1 \\
\hline 40161 & 0 & 0 & 208 & 31884 & 0.201923077 & 0.257142857 & 0.028571429 & 48957 & -1.01420934 & 0 & 0 \\
\hline 40162 & 0 & 0 & 6127 & 60615 & 0.223110821 & 0.173043693 & 0.231794619 & 0 & 0.024620378 & 0 & 0 \\
\hline 40165 & 6 & 0 & 34280 & 49400 & 0.211726954 & 0.264953955 & 0.157070316 & 103227 & 1.697082545 & 1 & 1 \\
\hline 40170 & 0 & 0 & 405 & 43201 & 0.22962963 & 0.381481481 & 0.092592593 & 8787 & -1.03444258 & 0 & 0 \\
\hline 40171 & 0 & 0 & 303 & 43201 & 0.234323432 & 0.396039604 & 0.094059406 & 16194 & -1.06176931 & 0 & 0 \\
\hline 40175 & 2 & 0 & 12507 & 43770 & 0.222675302 & 0.184064609 & 0.197444552 & 67767 & 0.527079046 & 0 & 0 \\
\hline 40176 & 0 & 0 & 810 & 31884 & 0.214814815 & 0.303867403 & 0.075506446 & 19331 & -0.95597398 & 0 & 0 \\
\hline 40177 & 0 & 0 & 2290 & 29315 & 0.19650655 & 0.342482845 & 0.095446039 & 51668 & -0.71114857 & 0 & 0 \\
\hline 40178 & 0 & 0 & 391 & 41981 & 0.191815857 & 0.308243728 & 0.11827957 & 24141 & -0.8701443 & 0 & 0 \\
\hline 40202 & 13 & 2 & 7106 & 11916 & 0.110188573 & 0.343690987 & 0.187639485 & 33916 & 1.069170846 & 1 & 1 \\
\hline 40203 & 4 & 0 & 17825 & 17351 & 0.240841515 & 0.358295229 & 0.136140109 & 60079 & 0.446111713 & 0 & 0 \\
\hline 40204 & 4 & 1 & 14941 & 38911 & 0.137072485 & 0.176480585 & 0.412779336 & 121279 & 1.267589726 & 1 & 0 \\
\hline 40205 & 8 & 2 & 24570 & 65369 & 0.156532357 & 0.059550019 & 0.5662353 & 167941 & 2.639899671 & 2 & 3 \\
\hline 40206 & 4 & 0 & 18491 & 40722 & 0.152128062 & 0.148619212 & 0.451408896 & 121224 & 1.468090144 & 1 & 0 \\
\hline 40207 & 40 & 8 & 29270 & 55518 & 0.175264776 & 0.051318768 & 0.574021895 & 177401 & 6.210979923 & 2 & 4 \\
\hline 40208 & 3 & 0 & 15050 & 23678 & 0.179003322 & 0.268248008 & 0.276215771 & 85401 & 0.658004202 & 0 & 0 \\
\hline 40209 & 0 & 0 & 1734 & 34096 & 0.189734717 & 0.282714055 & 0.179321486 & 26351 & -0.63002221 & 0 & 0 \\
\hline 40210 & 2 & 0 & 13671 & 21196 & 0.239119304 & 0.33542929 & 0.111352464 & 44123 & 0.061374299 & 0 & 0 \\
\hline 40211 & 4 & 0 & 24922 & 22573 & 0.255035711 & 0.301121265 & 0.1354592 & 56993 & 0.759589904 & 0 & 0 \\
\hline 40212 & 4 & 0 & 17781 & 25823 & 0.242674765 & 0.385630237 & 0.102335532 & 49574 & 0.430383829 & 0 & 0 \\
\hline 40213 & 7 & 1 & 16845 & 36400 & 0.199762541 & 0.221918977 & 0.226268657 & 87628 & 1.249735898 & 1 & 0 \\
\hline 40214 & 12 & 4 & 45282 & 37041 & 0.214168985 & 0.228073014 & 0.185351803 & 103424 & 2.575864772 & 2 & 1 \\
\hline 40215 & 8 & 0 & 21166 & 28452 & 0.247614098 & 0.300647273 & 0.114500409 & 64836 & 1.134404732 & 1 & 0 \\
\hline 40216 & 20 & 2 & 39512 & 37931 & 0.21079672 & 0.237892634 & 0.140996707 & 85270 & 3.228463449 & 2 & 2 \\
\hline 40217 & 10 & 1 & 12062 & 35463 & 0.153374233 & 0.194656489 & 0.270010905 & 83291 & 1.494749016 & 1 & 1 \\
\hline 40218 & 10 & 1 & 32002 & 35952 & 0.222673583 & 0.163286098 & 0.290960452 & 81626 & 2.136279905 & 2 & 0 \\
\hline 40219 & 9 & 3 & 36714 & 40994 & 0.213869369 & 0.217960561 & 0.18073015 & 88970 & 2.049328294 & 1 & 3 \\
\hline 40220 & 24 & 3 & 32271 & 47087 & 0.178767314 & 0.096302884 & 0.407318003 & 127099 & 4.122691534 & 2 & 3 \\
\hline
\end{tabular}




\begin{tabular}{|c|c|c|c|c|c|c|c|c|c|c|c|}
\hline 40222 & 19 & 2 & 22570 & 59722 & 0.168763846 & 0.077990944 & 0.520376549 & 181741 & 3.680698514 & 2 & 2 \\
\hline 40223 & 14 & 2 & 22222 & 66373 & 0.202097021 & 0.062787832 & 0.534864111 & 155988 & 3.113475971 & 2 & 4 \\
\hline 40228 & 3 & 0 & 17557 & 56316 & 0.219285755 & 0.137843121 & 0.260814141 & 96258 & 1.131517492 & 1 & 0 \\
\hline 40229 & 6 & 0 & 37656 & 47510 & 0.235872105 & 0.209921799 & 0.177704464 & 89663 & 1.782910338 & 1 & 1 \\
\hline 40231 & 0 & 0 & 86 & 27018 & 0.186046512 & 0.359375 & 0.140625 & 0 & -1.17923107 & 0 & 0 \\
\hline 40241 & 9 & 2 & 30903 & 79439 & 0.210432644 & 0.046001516 & 0.571868486 & 162552 & 3.002901191 & 2 & 3 \\
\hline 40242 & 4 & 0 & 9712 & 53679 & 0.182660626 & 0.071926765 & 0.467596629 & 111926 & 1.255911569 & 1 & 0 \\
\hline 40243 & 15 & 3 & 9478 & 59513 & 0.189702469 & 0.075292723 & 0.490884838 & 132723 & 2.562221853 & 2 & 4 \\
\hline 40245 & 4 & 1 & 28218 & 95395 & 0.243071798 & 0.059054465 & 0.582139895 & 221095 & 2.616777428 & 2 & 1 \\
\hline 40258 & 4 & 0 & 26102 & 47395 & 0.216726688 & 0.212331494 & 0.15243729 & 92373 & 1.247140636 & 1 & 2. \\
\hline 40272 & 3 & 0 & 37906 & 43206 & 0.216219068 & 0.239390387 & 0.148964439 & 98435 & 1.405714047 & 1 & 0 \\
\hline 40280 & 0 & 0 & 96 & 65992 & 0.135416667 & 0 & 0.8666666667 & 0 & 0.368588195 & 0 & 0 \\
\hline 40291 & 12 & 2 & 34723 & 60225 & 0.209025718 & 0.119858841 & 0.309078688 & 117824 & 2.804496862 & 2 & 1 \\
\hline 40299 & 15 & 0 & 40905 & 65763 & 0.215377093 & 0.097833129 & 0.38730113 & 128428 & 3.459517237 & 2 & 0 \\
\hline 40310 & 0 & 0 & 66 & 35908 & 0.212121212 & 0.204545455 & 0.136363636 & 34233 & -0.91715477 & 0 & 0 \\
\hline 40311 & 0 & 0 & 6515 & 36310 & 0.214121259 & 0.347982063 & 0.130044843 & 60819 & -0.29802299 & 0 & 0 \\
\hline 40312 & 0 & 0 & 5592 & 31436 & 0.226037196 & 0.485334058 & 0.056219446 & 63056 & -0.62121614 & 0 & 0 \\
\hline 40313 & 0 & 0 & 3210 & 28246 & 0.185669782 & 0.305346885 & 0.262041538 & 49070 & -0.41194632 & 0 & 0 \\
\hline 40316 & 0 & 0 & 229 & 35137 & 0.192139738 & 0.37654321 & 0.166666667 & 16623 & -1.00756188 & 0 & 0 \\
\hline 40322 & 0 & 0 & 3278 & 29641 & 0.199511897 & 0.445081606 & 0.076753419 & 48974 & -0.74690379 & 0 & 0 \\
\hline 40324 & 16 & 2 & 42398 & 61278 & 0.243714326 & 0.196485392 & 0.283157362 & 116761 & 3.295728078 & 2 & 3 \\
\hline 40328 & 0 & 0 & 1193 & 46136 & 0.213746857 & 0.364864865 & 0.141277641 & 22465 & -0.74974314 & 0 & 0 \\
\hline 40330 & 5 & 1 & 19724 & 43394 & 0.210048672 & 0.259100007 & 0.17606939 & 88345 & 1.095226496 & 1 & 1 \\
\hline 40334 & 0 & 0 & 40 & 29828 & 0.25 & 0.4444444444 & 0.074074074 & 6500 & -1.39745053 & 0 & 0 \\
\hline 40336 & 3 & 0 & 12338 & 27442 & 0.204409142 & 0.411564226 & 0.09813139 & 54429 & 0.145793622 & 0 & 1 \\
\hline 40337 & 0 & 0 & 5241 & 29828 & 0.232589201 & 0.410069849 & 0.067811409 & 63313 & -0.57998036 & 0 & 0 \\
\hline 40339 & 0 & 0 & 14 & 81749 & 0.214285714 & 0 & 0.333333333 & 0 & -0.22047544 & 0 & 0 \\
\hline 40342 & 6 & 1 & 21049 & 52300 & 0.221293173 & 0.203322729 & 0.188335101 & 95227 & 1.399105844 & 1 & 0 \\
\hline 40346 & 0 & 0 & 532 & 29641 & 0.231203008 & 0.433048433 & 0.068376068 & 38415 & -1.13672145 & 0 & 0 \\
\hline 40347 & 1 & 0 & 2973 & 54336 & 0.193407333 & 0.19895288 & 0.376487387 & 105860 & 0.258186344 & 0 & 0 \\
\hline 40348 & 0 & 0 & 213 & 29870 & 0.230046948 & 0.262411348 & 0.156028369 & 31013 & -0.97150059 & 0 & 0 \\
\hline 40350 & 0 & 0 & 280 & 43773 & 0.246428571 & 0.426966292 & 0.101123596 & 10213 & -1.11350383 & 0 & 0 \\
\hline 40351 & 7 & 1 & 20488 & 32771 & 0.16546271 & 0.277655384 & 0.288871086 & 82582 & 1.388931649 & 1 & 1 \\
\hline 40353 & 10 & 2 & 21228 & 43978 & 0.216694931 & 0.262162722 & 0.193706438 & 85546 & 1.70070968 & 1 & 2 \\
\hline 40356 & 13 & 3 & 42775 & 51445 & 0.233150205 & 0.211546732 & 0.249534117 & 125525 & 2.870001289 & 2 & 2 \\
\hline 40358 & 0 & 0 & 803 & 25624 & 0.215442092 & 0.418943534 & 0.122040073 & 20781 & -1.07163853 & 0 & 0 \\
\hline 40359 & 3 & 0 & 7317 & 42930 & 0.210878775 & 0.31511254 & 0.125 & 67009 & 0.180572601 & 0 & 0 \\
\hline 40360 & 0 & 0 & 7004 & 33893 & 0.22558538 & 0.389301634 & 0.140734451 & 64294 & -0.32470067 & 0 & 0 \\
\hline 40361 & 7 & 1. & 19142 & 39046 & 0.212099049 & 0.246683122 & 0.182813946 & 88724 & 1.273145142 & 1 & 1 \\
\hline 40363 & 0 & 0 & 1 & 53911 & 0 & 0 & 0 & 3213 & 0 & 0 & 0 \\
\hline 40370 & 0 & 0 & 3083 & 60332 & 0.209860525 & 0.215267899 & 0.184447606 & 47931 & -0.16486688 & 0 & 0 \\
\hline 40371 & 0 & 0 & 3147 & 22277 & 0.217032094 & 0.41350211 & 0.114861697 & 62590 & -0.74078284 & 0 & 0 \\
\hline 40372 & 0 & 0 & 2244 & 63843 & 0.187165775 & 0.197121402 & 0.182102628 & 65084 & -0.13150577 & 0 & 0 \\
\hline 40374 & 0 & 0 & 1717 & 22940 & 0.205591147 & 0.431623932 & 0.103418803 & 53590 & -0.91421009 & 0 & 0 \\
\hline 40376 & 0 & 0 & 184 & 26545 & 0.201086957 & 0.433070866 & 0.102362205 & 620 & -1.27115899 & 0 & 0 \\
\hline 40379 & 0 & 0 & 3619 & 65692 & 0.218292346 & 0.244462674 & 0.191960623 & 82683 & -0.02244363 & 0 & 0 \\
\hline 40380 & 0 & 0 & 6851 & 27376 & 0.208582689 & 0.402777778 & 0.113461538 & 69874 & -0.40156552 & 0 & 0 \\
\hline 40383 & 8 & 2 & 23196 & 56474 & 0.213053975 & 0.180630774 & 0.310608474 & 122620 & 1.952449006 & 1 & 1 \\
\hline 40385 & 0 & 0 & 3002 & 42098 & 0.194870087 & 0.363112392 & 0.15129683 & 63394 & -0.46079498 & 0 & 0 \\
\hline 40387 & 0 & 0 & 2437 & 30779 & 0.202708248 & 0.428741093 & 0.1347981 & 48393 & -0.73940262 & 0 & 0 \\
\hline 40390 & 1 & 0 & 6637 & 43524 & 0.197227663 & 0.116345311 & 0.517528484 & 105249 & 0.650248635 & 0 & 0 \\
\hline 40391 & 11 & 2 & 35404 & 47179 & 0.208592249 & 0.243243243 & 0.207700852 & 101803 & 2.330314098 & 2 & 2 \\
\hline 40402 & 0 & 0 & 2419 & 25966 & 0.211244316 & 0.397103199 & 0.117079059 & 39728 & -0.80238941 & 0 & 0 \\
\hline 40403 & 7 & 1 & 23176 & 45082 & 0.204219883 & 0.280181372 & 0.229233579 & 77447 & 1.462368833 & 1 & 1 \\
\hline 40404 & 0 & 0 & 194 & 51274 & 0.118556701 & 0.315789474 & 0.302631579 & 0 & -0.62130543 & 0 & 0 \\
\hline 40409 & 0 & 0 & 3760 & 18143 & 0.203457447 & 0.380422265 & 0.12706334 & 45048 & -0.7061134 & 0 & 0 \\
\hline 40419 & 0 & 0 & 4622 & 33770 & 0.225010818 & 0.416775457 & 0.115208877 & 40263 & -0.58686318 & 0 & 0 \\
\hline 40422 & 13 & 0 & 24594 & 36808 & 0.189273807 & 0.22332492 & 0.264054612 & 94155 & 2.239010189 & 2 & 2 \\
\hline 40434 & 0 & 0 & 4 & 23334 & 0.25 & 0 & 0 & 0 & -1.16051639 & 0 & 0 \\
\hline 40437 & 0 & 0 & 4872 & 27131 & 0.202586207 & 0.386504883 & 0.102397159 & 34435 & -0.60004488 & 0 & 0 \\
\hline 40440 & 0 & 0 & 1578 & 34195 & 0.205323194 & 0.366079703 & 0.091751622 & 36660 & -0.81821165 & 0 & 0 \\
\hline
\end{tabular}




\begin{tabular}{|c|c|c|c|c|c|c|c|c|c|c|c|}
\hline 40442 & 0 & 0 & 1226 & 27131 & 0.2137031 & 0.422569028 & 0.06362545 & 15376 & -1.07084165 & 0 & 0 \\
\hline 40444 & 1 & 0 & 13968 & 43301 & 0.197666094 & 0.290111463 & 0.158809694 & 87687 & 0.405026294 & 0 & 0 \\
\hline 40445 & 0 & 0 & 1215 & 14621 & 0.194238683 & 0.455075846 & 0.073512252 & 26655 & -1.15587289 & 0 & 0 \\
\hline 40447 & 0 & 0 & 8744 & 23334 & 0.204711802 & 0.479542819 & 0.087129369 & 43596 & -0.49261663 & 0 & 0 \\
\hline 40448 & 0 & 0 & 25 & 20026 & 0.2 & 0.388888889 & 0.055555556 & 0 & -1.42010506 & 0 & 0 \\
\hline 40456 & 1 & 0 & 9676 & 25495 & 0.202149649 & 0.427589299 & 0.101629054 & 52077 & -0.22814205 & 0 & 0 \\
\hline 40460 & 0 & 0 & 1099 & 17082 & 0.192902639 & 0.45691906 & 0.067885117 & 14356 & -1.18510792 & 0 & 0 \\
\hline 40461 & 0 & 0 & 3737 & 48239 & 0.209526358 & 0.256087981 & 0.24666143 & 45294 & -0.19606968 & 0 & 0 \\
\hline 40464 & 0 & 0 & 1356 & 39852 & 0.200589971 & 0.299363057 & 0.116772824 & 46264 & -0.67635577 & 0 & 0 \\
\hline 40468 & 0 & 0 & 1681 & 43394 & 0.205234979 & 0.25432526 & 0.216262976 & 55240 & -0.43750486 & 0 & 0 \\
\hline 40472 & 0 & 0 & 2487 & 25317 & 0.180538802 & 0.419662921 & 0.115730337 & 33654 & -0.80297376 & 0 & 0 \\
\hline 40475 & 15 & 2 & 56564 & 36137 & 0.181033873 & 0.211996428 & 0.298670371 & 106331 & 3.322688596 & 2 & 5 \\
\hline 40481 & 0 & 0 & 120 & 22083 & 0.208333333 & 0.50617284 & 0.074074074 & 9281 & -1.42641942 & 0 & 0 \\
\hline 40484 & 2 & 0 & 13035 & 32194 & 0.219716149 & 0.309920182 & 0.143443558 & 59690 & 0.250688261 & 0 & 0 \\
\hline 40486 & 0 & 0 & 2366 & 30361 & 0.210481826 & 0.508739076 & 0.084269663 & 48766 & -0.89091082 & 0 & 0 \\
\hline 40489 & 0 & 0 & 3562 & 32510 & 0.211678832 & 0.379182156 & 0.092110698 & 365 & -0.74318037 & 0 & 0 \\
\hline 40502 & 20 & 1 & 26730 & 46127 & 0.145491957 & 0.082646643 & 0.594080648 & 43734 & 3.582808054 & 2 & 0 \\
\hline 40503 & 41 & 5 & 27673 & 53519 & 0.171683591 & 0.082646667 & 0.477623723 & 185425 & 6.144491735 & 2 & 3 \\
\hline 40504 & 7 & 0 & 26674 & 29287 & 0.189023019 & 0.228691099 & 0.332146597 & 116308 & 1.697944686 & 1 & 0 \\
\hline 40505 & 3 & 0 & 25754 & 34189 & 0.193639823 & 0.268464502 & 0.195597138 & 99580 & 1.045484333 & 1 & 0 \\
\hline 40506 & 0 & 0 & 1008 & 20165 & 0.049603175 & 0.068527919 & 0.64213198 & 82612 & 0.153523059 & 0 & 0 \\
\hline 40507 & 1 & 0 & 2487 & 17217 & 0.087253719 & 0.219165085 & 0.358159393 & 43954 & -0.17504971 & 0 & 0 \\
\hline 40508 & 8 & 1 & 22862 & 19052 & 0.118799755 & 0.244821943 & 0.390766973 & 98292 & 1.6875382 & 1 & 1 \\
\hline 40509 & 15 & 2 & 33380 & 70674 & 0.214409826 & 0.10519458 & 0.513811675 & 151146 & 3.497359684 & 2 & 3 \\
\hline 40510 & 0 & 0 & 2438 & 65561 & 0.134126333 & 0.154249738 & 0.408709339 & 172210 & 0.49903833 & 0 & 0 \\
\hline 40511 & 4 & 0 & 33165 & 46252 & 0.209136137 & 0.221540887 & 0.283999825 & 89567 & 1.572151939 & 1 & 0 \\
\hline 40513 & 4 & 1 & 10663 & 89505 & 0.222639032 & 0.036988874 & 0.639069499 & 214165 & 2.028733591 & 1 & 1 \\
\hline 40514 & 3 & 0 & 14058 & 65811 & 0.237871674 & 0.039089395 & 0.590893948 & 141422 & 1.617171534 & 1 & 0 \\
\hline 40515 & 1 & 0 & 35947 & 54181 & 0.215650819 & 0.059538525 & 0.554182118 & 147280 & 1.962321495 & 1 & 0 \\
\hline 40516 & 0 & 0 & 2864 & 66908 & 0.202164804 & 0.182092555 & 0.38028169 & 93759 & 0.233247588 & 0 & 0 \\
\hline 40517 & 14 & 4 & 34412 & 33392 & 0.201790073 & 0.099950025 & 0.403964684 & 95614 & 2.856194228 & 2 & 4 \\
\hline 40601 & 14 & 3 & 49292 & 48784 & 0.192242149 & 0.205927791 & 0.279996567 & 102110 & 3.135447114 & 2 & 3 \\
\hline 40604 & 0 & 0 & 220 & 36502 & 0.109090909 & 0.296089385 & 0.201117318 & 0 & -0.82391066 & 0 & 0 \\
\hline 40701 & 10 & 2 & 28916 & 28639 & 0.2171808 & 0.342221311 & 0.159470824 & 71605 & 1.652426581 & 1 & 4 \\
\hline 40729 & 0 & 0 & 5605 & 30843 & 0.217662801 & 0.49774476 & 0.078535421 & 53462 & -0.62578481 & 0 & 0 \\
\hline 40734 & 0 & 0 & 3579 & 28882 & 0.215982118 & 0.457309454 & 0.095793419 & 47988 & -0.74151814 & 0 & 0 \\
\hline 40737 & 0 & 0 & 1619 & 39706 & 0.223594812 & 0.367100372 & 0.100371747 & 33713 & -0.78398134 & 0 & 0 \\
\hline 40740 & 0 & 0 & 2942 & 38718 & 0.23521414 & 0.383133784 & 0.106715252 & 28234 & -0.69205105 & 0 & 0 \\
\hline 40741 & 12 & 1 & 21208 & 34504 & 0.201244813 & 0.364086897 & 0.143720299 & 73623 & 1.672081952 & 1 & 3 \\
\hline 40743 & 0 & 0 & 362 & 47066 & 0.223756906 & 0.338842975 & 0.198347107 & 74923 & -0.69556755 & 0 & 0 \\
\hline 40744 & 0 & 0 & 18961 & 36432 & 0.220874426 & 0.310883281 & 0.170504732 & 33968 & 0.265178081 & 0 & 0 \\
\hline 40759 & 0 & 0 & 3481 & 18453 & 0.222637173 & 0.437609075 & 0.12609075 & 18522 & -0.86587169 & 0 & 0 \\
\hline 40763 & 0 & 0 & 467 & 29279 & 0.197002141 & 0.529411765 & 0.06501548 & 52680 & -1.17852561 & 0 & 0 \\
\hline 40769 & 4 & 0 & 19880 & 22967 & 0.2 & 0.431710914 & 0.159218289 & 16903 & 0.470722924 & 0 & 0 \\
\hline 40771 & 0 & 0 & 673 & 16817 & 0.200594354 & 0.512035011 & 0.070021882 & 8779 & -1.33034124 & 0 & 0 \\
\hline 40801 & 0 & 0 & 806 & 19535 & 0.196029777 & 0.560846561 & 0.15696649 & 3941 & -1.24137169 & 0 & 0 \\
\hline 40806 & 0 & 0 & 3458 & 30165 & 0.209369578 & 0.321398484 & 0.203454086 & 37864 & -0.50669031 & 0 & 0 \\
\hline 40807 & 0 & 0 & 45 & 28876 & 0.2 & 0.28125 & 0.25 & 10900 & -0.98423713 & 0 & 0 \\
\hline 40808 & 0 & 0 & 120 & 23912 & 0.2166666667 & 0.432098765 & 0.074074074 & 6167 & -1.35506327 & 0 & 0 \\
\hline 40810 & 0 & 0 & 1492 & 23912 & 0.205093834 & 0.424063116 & 0.105522682 & 34844 & -0.96567958 & 0 & 0 \\
\hline 40813 & 0 & 0 & 645 & 41040 & 0.195348837 & 0.397777778 & 0.122222222 & 16532 & -0.92842607 & 0 & 0 \\
\hline 40815 & 0 & 0 & 1550 & 25424 & 0.225806452 & 0.459615385 & 0.073076923 & 31351 & -1.04701025 & 0 & 0 \\
\hline 40816 & 0 & 0 & 230 & 19486 & 0.173913043 & 0.472727273 & 0.072727273 & 2444 & -1.35319158 & 0 & 0 \\
\hline 40818 & 0 & 0 & 411 & 35962 & 0.218978102 & 0.38869258 & 0.098939929 & 2959 & -1.09850585 & 0 & 0 \\
\hline 40819 & 0 & 0 & 850 & 32113 & 0.198823529 & 0.475043029 & 0.072289157 & 20344 & -1.09601969 & 0 & 0 \\
\hline 40820 & 0 & 0 & 363 & 17413 & 0.228650138 & 0.53526971 & 0.049792531 & 14995 & -1.45478135 & 0 & 0 \\
\hline 40823 & 2 & 0 & 4575 & 24704 & 0.205245902 & 0.378506146 & 0.165143397 & 41079 & -0.33559861 & 0 & 0 \\
\hline 40824 & 0 & 0 & 365 & 20254 & 0.205479452 & 0.421686747 & 0.088353414 & 13707 & -1.252662 & 0 & 0 \\
\hline 40826 & 0 & 0 & 899 & 24057 & 0.202447164 & 0.586151369 & 0.085346216 & 27724 & -1.24076746 & 0 & 0 \\
\hline 40827 & 0 & 0 & 424 & 28161 & 0.195754717 & 0.465986395 & 0.12244898 & 16396 & -1.15641185 & 0 & 0 \\
\hline 40828 & 0 & 0 & 4386 & 23980 & 0.201550388 & 0.495480415 & 0.087378641 & 34314 & -0.78394406 & 0 & 0 \\
\hline
\end{tabular}




\begin{tabular}{|c|c|c|c|c|c|c|c|c|c|c|c|}
\hline 40829 & 0 & 0 & 214 & 30276 & 0.219626168 & 0.414965986 & 0.108843537 & 0 & -1.22612629 & 0 & 0 \\
\hline 40830 & 0 & 0 & 141 & 30276 & 0.212765957 & 0.4375 & 0.114583333 & 7668 & -1.24281588 & 0 & 0 \\
\hline 40831 & 5 & 1 & 4654 & 29505 & 0.201117318 & 0.388871811 & 0.163541346 & 55566 & 0.067561896 & 0 & 1 \\
\hline 40840 & 0 & 0 & 529 & 28161 & 0.20415879 & 0.430939227 & 0.135359116 & 7892 & -1.11441024 & 0 & 0 \\
\hline 40843 & 0 & 0 & 627 & 21491 & 0.202551834 & 0.508235294 & 0.011764706 & 9435 & -1.35775208 & 0 & 0 \\
\hline 40844 & 0 & 0 & 73 & 19486 & 0.178082192 & 0.461538462 & 0.076923077 & 4503 & -1.40203246 & 0 & 0 \\
\hline 40845 & 0 & 0 & 479 & 41040 & 0.185803758 & 0.396449704 & 0.142011834 & 20231 & -0.92000363 & 0 & 0 \\
\hline 40847 & 0 & 0 & 60 & 43615 & 0.216666667 & 0.575 & 0.075 & 2518 & -1.35703403 & 0 & 0 \\
\hline 40849 & 0 & 0 & 40 & 27509 & 0.225 & 0.538461538 & 0.115384615 & 0 & -1.45036962 & 0 & 0 \\
\hline 40854 & 0 & 0 & 935 & 23673 & 0.188235294 & 0.272321429 & 0.242559524 & 24725 & -0.7532288 & 0 & 0 \\
\hline 40855 & 0 & 0 & 801 & 24080 & 0.207240949 & 0.294010889 & 0.20508167 & 26688 & -0.8510764 & 0 & 0 \\
\hline 40856 & 0 & 0 & 1149 & 21557 & 0.174934726 & 0.419082126 & 0.138888889 & 17519 & -0.99599852 & 0 & 0 \\
\hline 40858 & 0 & 0 & 590 & 28161 & 0.203389831 & 0.435960591 & 0.15270936 & 4497 & -1.09488996 & 0 & 0 \\
\hline 40862 & 0 & 0 & 544 & 34875 & 0.204044118 & 0.407407407 & 0.116402116 & 18972 & -1.02359449 & 0 & 0 \\
\hline 40863 & 0 & 0 & 437 & 24161 & 0.162471396 & 0.451713396 & 0.080996885 & 21544 & -1.16931203 & 0 & 0 \\
\hline 40865 & 0 & 0 & 143 & 30165 & 0.195804196 & 0.346534653 & 0.128712871 & 17886 & -1.0959365 & 0 & 0 \\
\hline 40868 & 0 & 0 & 744 & 28161 & 0.188172043 & 0.460076046 & 0.1121673 & 20265 & -1.07931617 & 0 & 0 \\
\hline 40870 & 0 & 0 & 257 & 40995 & 0.186770428 & 0.309782609 & 0.184782609 & 35803 & -0.81180888 & 0 & 0 \\
\hline 40873 & 0 & 0 & 2369 & 32113 & 0.193752638 & 0.431927711 & 0.104819277 & 35336 & -0.78941859 & 0 & 0 \\
\hline 40874 & 0 & 0 & 760 & 14746 & 0.192105263 & 0.50094162 & 0.094161959 & 17460 & -1.26617477 & 0 & 0 \\
\hline 40902 & 0 & 0 & 1216 & 19277 & 0.216282895 & 0.599759615 & 0.050480769 & 17700 & -1.32624445 & 0 & 0 \\
\hline 40903 & 0 & 0 & 581 & 17110 & 0.213425129 & 0.417721519 & 0.060759494 & 16685 & -1.26074769 & 0 & 0 \\
\hline 40906 & 6 & 0 & 11428 & 17110 & 0.218673434 & 0.433952461 & 0.11897649 & 54637 & 0.326527271 & 0 & 0 \\
\hline 40913 & 0 & 0 & 292 & 13484 & 0.20890411 & 0.509803922 & 0.088235294 & 5773 & -1.44045775 & 0 & 0 \\
\hline 40914 & 0 & 0 & 449 & 28444 & 0.204899777 & 0.594771242 & 0.088235294 & 7845 & -1.3407149 & 0 & 0 \\
\hline 40915 & 0 & 0 & 1465 & 31359 & 0.227303754 & 0.434196891 & 0.176165803 & 37223 & -0.85652637 & 0 & 0 \\
\hline 40921 & 0 & 0 & 382 & 17466 & 0.230366492 & 0.586614173 & 0.094488189 & 8929 & -1.46692034 & 0 & 0 \\
\hline 40923 & 0 & 0 & 425 & 28124 & 0.230588235 & 0.476702509 & 0.046594982 & 41923 & -1.23120293 & 0 & 0 \\
\hline 40927 & 0 & 0 & 239 & 21491 & 0.20083682 & 0.512345679 & 0.012345679 & 19088 & -1.42968661 & 0 & 0 \\
\hline 40935 & 0 & 0 & 3161 & 15992 & 0.233470421 & 0.574879227 & 0.065700483 & 29133 & -1.10182343 & 0 & 0 \\
\hline 40939 & 0 & 0 & 520 & 15571 & 0.2 & 0.582633053 & 0.070028011 & 10188 & -1.43648961 & 0 & 0 \\
\hline 40940 & 0 & 0 & 583 & 14244 & 0.202401372 & 0.580645161 & 0.064516129 & 11287 & -1.43963108 & 0 & 0 \\
\hline 40941 & 0 & 0 & 263 & 14642 & 0.174904943 & 0.560209424 & 0.073298429 & 0 & -1.47729433 & 0 & 0 \\
\hline 40943 & 0 & 0 & 343 & 28681 & 0.239067055 & 0.518018018 & 0.108108108 & 10915 & -1.30120157 & 0 & 0 \\
\hline 40946 & 0 & 0 & 572 & 35933 & 0.230769231 & 0.532085561 & 0.053475936 & 0 & -1.27272695 & 0 & 0 \\
\hline 40949 & 0 & 0 & 1110 & 16623 & 0.218018018 & 0.445187166 & 0.058823529 & 9904 & -1.22562099 & 0 & \\
\hline 40953 & 0 & 0 & 585 & 35933 & 0.230769231 & 0.533854167 & 0.028645833 & 12778 & -1.26936922 & 0 & 0 \\
\hline 40958 & 0 & 0 & 254 & 28247 & 0.208661417 & 0.572254335 & 0.069364162 & 10807 & -1.3895028 & 0 & 0 \\
\hline 40962 & 2 & 0 & 19541 & 27159 & 0.192825342 & 0.491099324 & 0.101213398 & 51720 & 0.245208391 & 0 & 0 \\
\hline 40964 & 0 & 0 & 129 & 30276 & 0.224806202 & 0.431818182 & 0.125 & 0 & -1.26271218 & 0 & 0 \\
\hline 40965 & 6 & 1 & 13422 & 21425 & 0.199150648 & 0.39344086 & 0.139032258 & 62803 & 0.554345644 & 0 & 1 \\
\hline 40972 & 0 & 0 & 1017 & 24440 & 0.175024582 & 0.574555404 & 0.054719562 & 22906 & -1.21985851 & 0 & 0 \\
\hline 40977 & 2 & 0 & 9808 & 26828 & 0.182911909 & 0.454235845 & 0.117071094 & 47994 & -0.09636003 & 0 & 0 \\
\hline 40979 & 0 & 0 & 47 & 14746 & 0.191489362 & 0.545454545 & 0.060606061 & 4476 & -1.57555029 & 0 & 0 \\
\hline 40982 & 0 & 0 & 166 & 13304 & 0.253012048 & 0.611650485 & 0.048543689 & 13343 & -1.65894935 & 0 & 0 \\
\hline 40983 & 0 & 0 & 608 & 10381 & 0.208881579 & 0.485365854 & 0.068292683 & 4696 & -1.39510077 & 0 & 0 \\
\hline 40988 & 0 & 0 & 649 & 28247 & 0.204930663 & 0.533632287 & 0.094170404 & 21088 & -1.20469031 & 0 & 0 \\
\hline 40995 & 0 & 0 & 85 & 16590 & 0.176470588 & 0.5 & 0.083333333 & 0 & -1.46016101 & 0 & 0 \\
\hline 40997 & 0 & 0 & 392 & 15992 & 0.219387755 & 0.625954198 & 0.061068702 & 11144 & -1.53412275 & 0 & 0 \\
\hline 41001 & 4 & 0 & 14714 & 61102 & 0.225023787 & 0.165995248 & 0.227455841 & 126486 & 1.174402239 & 1 & 1 \\
\hline 41002 & 0 & 0 & 2646 & 31469 & 0.225623583 & 0.289830508 & 0.153107345 & 65601 & -0.54554928 & 0 & 0 \\
\hline 41003 & 0 & 0 & 3173 & 35937 & 0.231957138 & 0.287428023 & 0.077255278 & 40999 & -0.60234988 & 0 & 0 \\
\hline 41004 & 0 & 0 & 4234 & 35185 & 0.225555031 & 0.309388336 & 0.142958748 & 57865 & -0.42820842 & 0 & 0 \\
\hline 41005 & 5 & 2 & 26184 & 68123 & 0.257294531 & 0.115802982 & 0.296871181 & 130373 & 1.833986805 & 1 & 1 \\
\hline 41006 & 0 & 0 & 4110 & 64877 & 0.208272506 & 0.277878022 & 0.155900397 & 64532 & -0.09304839 & 0 & 0 \\
\hline 41007 & 0 & 0 & 5175 & 73095 & 0.230917874 & 0.18130396 & 0.201250372 & 93265 & 0.238544598 & 0 & 0 \\
\hline 41008 & 5 & 1 & 6960 & 33549 & 0.222988506 & 0.300535906 & 0.114469453 & 87298 & 0.330847133 & 0 & 1 \\
\hline 41010 & 0 & 0 & 3132 & 43575 & 0.22541507 & 0.350868726 & 0.089285714 & 43666 & -0.57272675 & 0 & 0 \\
\hline 41011 & 11 & 0 & 26229 & 41078 & 0.192725609 & 0.235757543 & 0.273594512 & 96734 & 2.107867712 & 2 & 0 \\
\hline 41014 & 2 & 0 & 6854 & 42478 & 0.212722498 & 0.284313725 & 0.159846547 & 58906 & 0.087355575 & 0 & 0 \\
\hline 41015 & 3 & 0 & 21227 & 52482 & 0.211852829 & 0.232778933 & 0.200900901 & 109152 & 1.106258345 & 1 & 0 \\
\hline
\end{tabular}




\begin{tabular}{|c|c|c|c|c|c|c|c|c|c|c|c|}
\hline 41016 & 0 & 0 & 5477 & 44039 & 0.213985759 & 0.217626386 & 0.196809949 & 68202 & -0.07797636 & 0 & 0 \\
\hline 41017 & 15 & 2 & 41118 & 65133 & 0.219368646 & 0.088854276 & 0.42760894 & 151089 & 3.558898915 & 2 & 2 \\
\hline 41018 & 8 & 0 & 25674 & 50869 & 0.234439511 & 0.186476868 & 0.222360617 & 95900 & 1.791495936 & 1 & 0 \\
\hline 41030 & 1 & 0 & 6020 & 56403 & 0.254983389 & 0.223432519 & 0.172688629 & 78172 & 0.119433588 & 0 & 0 \\
\hline 41031 & 5 & 1 & 15809 & 41229 & 0.21399203 & 0.256147541 & 0.157507452 & 88318 & 0.91158557 & 1 & 0 \\
\hline 41033 & 0 & 0 & 2276 & 49368 & 0.210456942 & 0.272370999 & 0.112344873 & 34846 & -0.5026355 & 0 & 0 \\
\hline 41034 & 0 & 0 & 1108 & 40096 & 0.210288809 & 0.238410596 & 0.145695364 & 65106 & -0.58584173 & 0 & 0 \\
\hline 41035 & 3 & 0 & 11040 & 40581 & 0.255797101 & 0.283739018 & 0.13927697 & 85198 & 0.38410696 & 0 & 0 \\
\hline 41039 & 0 & 0 & 2584 & 32980 & 0.207043344 & 0.329358319 & 0.141396934 & 59812 & -0.58067656 & 0 & 0 \\
\hline 41040 & 1 & 0 & 7212 & 37082 & 0.214087632 & 0.287963538 & 0.121193288 & 75049 & -0.05942137 & 0 & 0 \\
\hline 41041 & 2 & 0 & 6605 & 29781 & 0.216199849 & 0.321468799 & 0.156341518 & 63914 & -0.07280063 & 0 & 0 \\
\hline 41042 & 24 & 2 & 48996 & 49593 & 0.234345661 & 0.138168129 & 0.293634497 & 118852 & 4.300981397 & 2 & 3 \\
\hline 41043 & 0 & 0 & 1916 & 58218 & 0.204592902 & 0.288855193 & 0.160727824 & 51650 & -0.38001922 & 0 & 0 \\
\hline 41044 & 0 & 0 & 1004 & 32624 & 0.21812749 & 0.30191458 & 0.184094256 & 29917 & -0.77800796 & 0 & 0 \\
\hline 41045 & 0 & 0 & 1957 & 41623 & 0.234542667 & 0.274371069 & 0.170597484 & 59125 & -0.51624706 & 0 & 0 \\
\hline 41046 & 0 & 0 & 1195 & 46944 & 0.246861925 & 0.322368421 & 0.081578947 & 44929 & -0.75277203 & 0 & 0 \\
\hline 41048 & 3 & 0 & 11369 & 106040 & 0.281291231 & 0.1336074 & 0.356922625 & 153288 & 1.490489906 & 1 & 0 \\
\hline 41049 & 0 & 0 & 2430 & 29708 & 0.221399177 & 0.381011097 & 0.085696671 & 54888 & -0.76340723 & 0 & 0 \\
\hline 41051 & 5 & 0 & 25749 & 62058 & 0.265447202 & 0.162393701 & 0.255055118 & 113531 & 1.628040384 & 1 & 1 \\
\hline 41052 & 0 & 0 & 89 & 44053 & 0.224719101 & 0.275862069 & 0.155172414 & 20234 & -0.92780923 & 0 & 0 \\
\hline 41055 & 0 & 0 & 1874 & 50982 & 0.220917823 & 0.277689873 & 0.210443038 & 68340 & -0.36502065 & 0 & 0 \\
\hline 41056 & 7 & 1 & 14368 & 37727 & 0.214922049 & 0.270799347 & 0.214620718 & 75087 & 1.058761353 & 1 & 1 \\
\hline 41059 & 0 & 0 & 3801 & 60053 & 0.211786372 & 0.161340608 & 0.233047545 & 56113 & 0.013671785 & 0 & 0 \\
\hline 41062 & 0 & 0 & 5 & 40096 & 0.2 & 0 & 0 & 0 & -0.95059071 & 0 & 0 \\
\hline 41063 & 0 & 0 & 3446 & 52428 & 0.211549623 & 0.235955056 & 0.171564391 & 87050 & -0.15051474 & 0 & 0 \\
\hline 41064 & 0 & 0 & 1936 & 36152 & 0.183884298 & 0.383009359 & 0.125989921 & 59913 & -0.66015591 & 0 & 0 \\
\hline 41071 & 6 & 0 & 21247 & 40301 & 0.1950393 & 0.266815386 & 0.193605083 & 65090 & 1.204302412 & 1 & 0 \\
\hline 41073 & 3 & 0 & 5885 & 46400 & 0.191503823 & 0.210016937 & 0.165255263 & 71644 & 0.305088119 & 0 & 0 \\
\hline 41074 & 1 & 0 & 5358 & 36278 & 0.223590892 & 0.300338409 & 0.10998308 & 61498 & -0.246586668 & 0 & 0 \\
\hline 41075 & 7 & 2 & 15562 & 59002 & 0.210127233 & 0.1145686 & 0.413295615 & 124734 & 1.782471548 & 1 & 2 \\
\hline 41076 & 4 & 1 & 17729 & 44131 & 0.167240115 & 0.150685981 & 0.334866253 & 114925 & 1.310447451 & 1 & 0 \\
\hline 41080 & 0 & 0 & 2834 & 77614 & 0.23288638 & 0.211611503 & 0.236028215 & 98649 & 0.115998557 & 0 & 0 \\
\hline 41083 & 0 & 0 & 1678 & 32142 & 0.23659118 & 0.307762557 & 0.109589041 & 29328 & -0.80188496 & 0 & 0 \\
\hline 41085 & 0 & 0 & 200 & 36356 & 0.235 & 0.246153846 & 0.146153846 & 49757 & -0.87574689 & 0 & 0 \\
\hline 41086 & 0 & 0 & 3528 & 42214 & 0.236678005 & 0.295731707 & 0.128484321 & 37858 & -0.48202894 & 0 & 0 \\
\hline 41091 & 4 & 0 & 18812 & 82738 & 0.260578354 & 0.087866471 & 0.415549598 & 145408 & 1.802387311 & 1 & 1 \\
\hline 41092 & 0 & 0 & 3263 & 61357 & 0.233527429 & 0.216697936 & 0.140243902 & 92525 & -0.11470611 & 0 & 0 \\
\hline 41093 & 0 & 0 & 2983 & 28570 & 0.2256118 & 0.355745108 & 0.117410938 & 45447 & -0.68968841 & 0 & 0 \\
\hline 41094 & 3 & 0 & 15166 & 50495 & 0.252802321 & 0.180049413 & 0.24387482 & 91601 & 0.879855502 & 1 & 0 \\
\hline 41095 & 0 & 0 & 2861 & 37835 & 0.236630549 & 0.322580645 & 0.089247312 & 71756 & -0.56884794 & 0 & 0 \\
\hline 41097 & 1 & 0 & 7270 & 40048 & 0.22957359 & 0.279365742 & 0.136031713 & 69453 & -0.0362514 & 0 & 0 \\
\hline 41098 & 0 & 0 & 1841 & 42214 & 0.207495926 & 0.319013524 & 0.105011933 & 50518 & -0.62656701 & 0 & 0 \\
\hline 41099 & 0 & 0 & 380 & 41583 & 0.076315789 & 0.087227414 & 0.510903427 & 0 & -0.15627775 & 0 & 0 \\
\hline 41101 & 17 & 0 & 17996 & 37642 & 0.199044232 & 0.237706218 & 0.228426396 & 63073 & 2.329262968 & 2 & 2 \\
\hline 41102 & 3 & 0 & 20923 & 39719 & 0.17956316 & 0.197435727 & 0.199893709 & 68061 & 0.95902354 & 1 & 0 \\
\hline 41121 & 0 & 0 & 1937 & 31354 & 0.199793495 & 0.402973978 & 0.093680297 & 50259 & -0.79799594 & 0 & 0 \\
\hline 41124 & 0 & 0 & 1111 & 31017 & 0.214221422 & 0.587217044 & 0.058588549 & 25106 & -1.19624139 & 0 & 0 \\
\hline 41129 & 1 & 0 & 11053 & 47181 & 0.19949335 & 0.216914138 & 0.205939316 & 59575 & 0.368603853 & 0 & 0 \\
\hline 41132 & 0 & 0 & 908 & 31194 & 0.231277533 & 0.364249578 & 0.094435076 & 5492 & -1.03514331 & 0 & 0 \\
\hline 41135 & 0 & 0 & 102 & 30858 & 0.205882353 & 0.444444444 & 0.055555556 & 921 & -1.33306249 & 0 & 0 \\
\hline 41139 & 4 & 0 & 7907 & 38431 & 0.184393575 & 0.227440633 & 0.164995602 & 13531 & 0.319311195 & 0 & 0 \\
\hline 41141 & 0 & 0 & 2604 & 27717 & 0.220430108 & 0.42799306 & 0.083863505 & 55126 & -0.81029487 & 0 & 0 \\
\hline 41142 & 0 & 0 & 22 & 29372 & 0.181818182 & 0.266666667 & 0 & 24676 & -1.20339349 & 0 & 0 \\
\hline 41143 & 4 & 0 & 14382 & 31194 & 0.202058128 & 0.318072047 & 0.15818072 & 61066 & 0.548358834 & 0 & 0 \\
\hline 41144 & 2 & 0 & 11186 & 44268 & 0.205167173 & 0.299831846 & 0.155219247 & 57877 & 0.312147352 & 0 & 0 \\
\hline 41146 & 0 & 0 & 157 & 31194 & 0.23566879 & 0.37254902 & 0.078431373 & 14351 & -1.21579455 & 0 & 0 \\
\hline 41149 & 1 & 0 & 656 & 21687 & 0.217987805 & 0.502283105 & 0.123287671 & 26817 & -1.09230433 & 0 & 0 \\
\hline 41159 & 0 & 0 & 512 & 31017 & 0.2265625 & 0.615384615 & 0.056213018 & 19358 & -1.35750071 & 0 & 0 \\
\hline 41164 & 0 & 0 & 13603 & 29196 & 0.204146144 & 0.417515924 & 0.104883227 & 52534 & -0.11577288 & 0 & 0 \\
\hline 41166 & 0 & 0 & 973 & 45293 & 0.214799589 & 0.305471125 & 0.085106383 & 22879 & -0.79314088 & 0 & 0 \\
\hline 41168 & 0 & 0 & 2924 & 39094 & 0.214774282 & 0.248481781 & 0.146255061 & 40131 & -0.46531834 & 0 & 0 \\
\hline
\end{tabular}




\begin{tabular}{|c|c|c|c|c|c|c|c|c|c|c|c|}
\hline 41169 & 4 & 0 & 5543 & 37851 & 0.191953816 & 0.179801071 & 0.223667432 & 59097 & 0.379911603 & 0 & 0 \\
\hline 41171 & 0 & 0 & 4427 & 31052 & 0.191777728 & 0.477674269 & 0.106007067 & 44501 & -0.64564924 & 0 & 0 \\
\hline 41174 & 0 & 0 & 1134 & 27780 & 0.188712522 & 0.290322581 & 0.115384615 & 36995 & -0.81444423 & 0 & 0 \\
\hline 41175 & 0 & 0 & 5540 & 32311 & 0.203249097 & 0.260744986 & 0.118520448 & 56191 & -0.32013035 & 0 & 0 \\
\hline 41179 & 2 & 0 & 8574 & 19358 & 0.209353861 & 0.45899134 & 0.080489047 & 40655 & -0.31729525 & 0 & 0 \\
\hline 41180 & 0 & 0 & 1354 & 21411 & 0.198670606 & 0.443266172 & 0.072110286 & 18178 & -1.09137867 & 0 & 0 \\
\hline 41183 & 0 & 0 & 1163 & 42251 & 0.185726569 & 0.193470375 & 0.165659008 & 54490 & -0.48913442 & 0 & 0 \\
\hline 41189 & 0 & 0 & 2291 & 28624 & 0.203841117 & 0.321026283 & 0.17146433 & 62463 & -0.59764549 & 0 & 0 \\
\hline 41201 & 0 & 0 & 284 & 22905 & 0.207746479 & 0.49 & 0.065 & 10624 & -1.35233826 & 0 & 0 \\
\hline 41203 & 0 & 0 & 560 & 19331 & 0.210714286 & 0.468586387 & 0.096858639 & 26617 & -1.229502 & 0 & 0 \\
\hline 41204 & 0 & 0 & 554 & 26598 & 0.216606498 & 0.372972973 & 0.091891892 & 34907 & -1.06635084 & 0 & 0 \\
\hline 41214 & 0 & 0 & 938 & 26921 & 0.207889126 & 0.438679245 & 0.160377358 & 22556 & -1.00260894 & 0 & 0 \\
\hline 41216 & 0 & 0 & 1678 & 31818 & 0.199046484 & 0.351054852 & 0.148523207 & 41194 & -0.7334244 & 0 & 0 \\
\hline 41219 & 0 & 0 & 1818 & 37059 & 0.215071507 & 0.402607987 & 0.076609617 & 37837 & -0.82511292 & 0 & 0 \\
\hline 41222 & 0 & 0 & 3334 & 28634 & 0.196760648 & 0.370593293 & 0.154342218 & 32675 & -0.62888444 & 0 & 0 \\
\hline 41224 & 0 & 0 & 6352 & 26024 & 0.16168136 & 0.441106031 & 0.154147616 & 48427 & -0.43095388 & 0 & 0 \\
\hline 41226 & 0 & 0 & 224 & 37059 & 0.227678571 & 0.391891892 & 0.074324324 & 15107 & -1.15216975 & 0 & 0 \\
\hline 41230 & 4 & 0 & 11564 & 23182 & 0.203562781 & 0.383045329 & 0.113448535 & 57670 & 0.235851212 & 0 & 0 \\
\hline 41231 & 0 & 0 & 609 & 19331 & 0.213464696 & 0.415458937 & 0.132850242 & 46845 & -1.08571387 & 0 & 0 \\
\hline 41232 & 0 & 0 & 642 & 26876 & 0.202492212 & 0.436651584 & 0.101809955 & 12290 & -1.13308182 & 0 & 0 \\
\hline 41234 & 0 & 0 & 579 & 37021 & 0.189982729 & 0.331719128 & 0.150121065 & 2228 & -0.9092909 & 0 & 0 \\
\hline 41238 & 0 & 0 & 1100 & 34458 & 0.206363636 & 0.389986825 & 0.108036891 & 12879 & -0.94085996 & 0 & 0 \\
\hline 41240 & 7 & 1 & 6365 & 26598 & 0.186017282 & 0.335375191 & 0.181141982 & 59266 & 0.469861211 & 0 & 1 \\
\hline 41250 & 0 & 0 & 1861 & 12817 & 0.194519076 & 0.511574074 & 0.090277778 & 31296 & -1.11809358 & 0 & 0 \\
\hline 41254 & 0 & 0 & 625 & 36584 & 0.2016 & 0.373303167 & 0.110859729 & 46579 & -0.89866782 & 0 & 0 \\
\hline 41255 & 0 & 0 & 1118 & 27092 & 0.191413238 & 0.544757033 & 0.076726343 & 34184 & -1.12167955 & 0 & 0 \\
\hline 41256 & 0 & 0 & 2609 & 37356 & 0.206975853 & 0.346904629 & 0.16787507 & 49541 & -0.5512324 & 0 & 0 \\
\hline 41257 & 0 & 0 & 568 & 22440 & 0.213028169 & 0.424479167 & 0.091145833 & 15837 & -1.19103382 & 0 & 0 \\
\hline 41260 & 0 & 0 & 380 & 23880 & 0.205263158 & 0.354961832 & 0.13740458 & 35934 & -1.04721098 & 0 & 0 \\
\hline 41262 & 0 & 0 & 1497 & 38767 & 0.225784903 & 0.424897119 & 0.116255144 & 29116 & -0.85937958 & 0 & 0 \\
\hline 41263 & 0 & 0 & 725 & 23880 & 0.204137931 & 0.357852883 & 0.125248509 & 35037 & -0.99197742 & 0 & 0 \\
\hline 41264 & 0 & 0 & 552 & 26876 & 0.197463768 & 0.44386423 & 0.09921671 & 26577 & -1.12201254 & 0 & 0 \\
\hline 41265 & 0 & 0 & 2049 & 37021 & 0.192776964 & 0.324982603 & 0.142658316 & 54323 & -0.58894976 & 0 & 0 \\
\hline 41267 & 0 & 0 & 1077 & 13954 & 0.252553389 & 0.48766328 & 0.09724238 & 55178 & -1.19006331 & 0 & 0 \\
\hline 41268 & 0 & 0 & 137 & 53493 & 0.189781022 & 0.28125 & 0.21875 & 22896 & -0.71111375 & 0 & 0 \\
\hline 41271 & 0 & 0 & 221 & 23880 & 0.212669683 & 0.362416107 & 0.120805369 & 28128 & -1.14388465 & 0 & 0 \\
\hline 41274 & 0 & 0 & 520 & 23223 & 0.203846154 & 0.368421053 & 0.11634349 & 41373 & -1.04275987 & 0 & 0 \\
\hline 41301 & 0 & 0 & 6540 & 15330 & 0.213914373 & 0.453789071 & 0.130425006 & 1242 & -0.72244004 & 0 & 0 \\
\hline 41311 & 0 & 0 & 7098 & 20647 & 0.165539589 & 0.479754366 & 0.093072347 & 51293 & -0.5364618 & 0 & 0 \\
\hline 41314 & 0 & 0 & 5580 & 19585 & 0.196774194 & 0.494038362 & 0.122861586 & 33157 & -0.6982023 & 0 & 0 \\
\hline 41317 & 0 & 0 & 338 & 16162 & 0.204142012 & 0.424369748 & 0.109243697 & 19904 & -1.26018867 & 0 & 0 \\
\hline 41332 & 0 & 0 & 1260 & 31196 & 0.207142857 & 0.428074246 & 0.099767981 & 26546 & -0.96278304 & 0 & 0 \\
\hline 41339 & 3 & 0 & 10261 & 19105 & 0.209043953 & 0.410083087 & 0.150260527 & 51829 & 0.023462506 & 0 & 0 \\
\hline 41348 & 0 & 0 & 1519 & 16621 & 0.204081633 & 0.5078125 & 0.086914063 & 25379 & -1.149354 & 0 & 0 \\
\hline 41352 & 0 & 0 & 781 & 31196 & 0.202304738 & 0.424074074 & 0.112962963 & 0 & -1.07310027 & 0 & 0 \\
\hline 41360 & 0 & 0 & 510 & 27084 & 0.225490196 & 0.526470588 & 0.097058824 & 8499 & -1.28595014 & 0 & 0 \\
\hline 41365 & 0 & 0 & 495 & 21606 & 0.236363636 & 0.476780186 & 0.126934985 & 26933 & -1.22756824 & 0 & 0 \\
\hline 41366 & 0 & 0 & 12 & 20942 & 0.25 & 0.25 & 0 & 0 & -1.41056999 & 0 & 0 \\
\hline 41367 & 0 & 0 & 272 & 37977 & 0.183823529 & 0.481865285 & 0.098445596 & 11353 & -1.1478568 & 0 & 0 \\
\hline 41385 & 0 & 0 & 394 & 15038 & 0.187817259 & 0.374100719 & 0.104316547 & 19074 & -1.19532493 & 0 & 0 \\
\hline 41390 & 0 & 0 & 46 & 18973 & 0.217391304 & 0.516129032 & 0.096774194 & 1882 & -1.50716481 & 0 & 0 \\
\hline 41397 & 0 & 0 & 54 & 20647 & 0.185185185 & 0.526315789 & 0.052631579 & 9735 & -1.48884304 & 0 & 0 \\
\hline 41408 & 0 & 0 & 253 & 56710 & 0.213438735 & 0.403508772 & 0.093567251 & 3076 & -0.96962039 & 0 & 0 \\
\hline 41421 & 0 & 0 & 272 & 34214 & 0.216911765 & 0.519337017 & 0.082872928 & 4897 & -1.28818537 & 0 & 0 \\
\hline 41425 & 0 & 0 & 905 & 29813 & 0.207734807 & 0.401284109 & 0.104333868 & 36003 & -0.97546945 & 0 & 0 \\
\hline 41464 & 0 & 0 & 456 & 12932 & 0.203947368 & 0.524271845 & 0.055016181 & 4032 & -1.45235392 & 0 & 0 \\
\hline 41465 & 2 & 0 & 12142 & 20571 & 0.209520672 & 0.494067797 & 0.089830508 & 57452 & -0.12162553 & 0 & 0 \\
\hline 41472 & 3 & 0 & 10609 & 28086 & 0.172589311 & 0.443907536 & 0.136084628 & 55267 & 0.122173406 & 0 & 0 \\
\hline 41501 & 15 & 2 & 22971 & 36927 & 0.187540812 & 0.332435741 & 0.191799266 & 82712 & 2.199388732 & 2 & 2 \\
\hline 41503 & 2 & 0 & 462 & 32503 & 0.158008658 & 0.17765043 & 0.252148997 & 68631 & -0.3049097 & 0 & 0 \\
\hline 41512 & 0 & 0 & 1054 & 37247 & 0.180265655 & 0.448871182 & 0.078353254 & 36918 & -0.92643942 & 0 & 0 \\
\hline
\end{tabular}




\begin{tabular}{|c|c|c|c|c|c|c|c|c|c|c|c|}
\hline 41513 & 0 & 0 & 693 & 17646 & 0.174603175 & 0.386 & 0.094 & 29427 & -1.09289581 & 0 & 0 \\
\hline 41514 & 0 & 0 & 3698 & 44925 & 0.20822066 & 0.292848582 & 0.141030763 & 47410 & -0.37255563 & 0 & 0 \\
\hline 41517 & 0 & 0 & 118 & 12776 & 0.220338983 & 0.328767123 & 0.136986301 & 0 & -1.30489097 & 0 & 0 \\
\hline 41519 & 0 & 0 & 938 & 45227 & 0.203624733 & 0.373643411 & 0.147286822 & 13887 & -0.8056361 & 0 & 0 \\
\hline 41522 & 0 & 0 & 5208 & 27646 & 0.183371736 & 0.4117806 & 0.081599568 & 50319 & -0.56066231 & 0 & 0 \\
\hline 41524 & 0 & 0 & 415 & 28710 & 0.197590361 & 0.520833333 & 0.048611111 & 17165 & -1.28741253 & 0 & 0 \\
\hline 41526 & 0 & 0 & 14 & 27976 & 0.214285714 & 0.1 & 0 & 0 & -1.15775794 & 0 & 0 \\
\hline 41527 & 0 & 0 & 697 & 47008 & 0.197991392 & 0.257142857 & 0.257142857 & 74812 & -0.45163745 & 0 & 0 \\
\hline 41528 & 0 & 0 & 860 & 29100 & 0.197674419 & 0.473244147 & 0.088628763 & 22834 & -1.09463928 & 0 & 0 \\
\hline 41531 & 0 & 0 & 1242 & 46616 & 0.183574879 & 0.304740406 & 0.17268623 & 33962 & -0.58445987 & 0 & 0 \\
\hline 41534 & 0 & 0 & 121 & 32779 & 0.20661157 & 0.407407407 & 0.049382716 & 8054 & -1.26239506 & 0 & 0 \\
\hline 41535 & 0 & 0 & 327 & 30446 & 0.198776758 & 0.318584071 & 0.150442478 & 30577 & -0.95767849 & 0 & 0 \\
\hline 41537 & 0 & 0 & 5488 & 27527 & 0.191144315 & 0.382122321 & 0.12990068 & 52633 & -0.46573831 & 0 & 0 \\
\hline 41538 & 0 & 0 & 18 & 27527 & 0.166666667 & 0.083333333 & 0 & 6814 & -1.06935997 & 0 & 0 \\
\hline 41539 & 0 & 0 & 1877 & 36853 & 0.207245605 & 0.387897595 & 0.076027929 & 45117 & -0.78074167 & 0 & 0 \\
\hline 41540 & 0 & 0 & 372 & 42760 & 0.180107527 & 0.455223881 & 0.093283582 & 19882 & -1.03397004 & 0 & 0 \\
\hline 41543 & 0 & 0 & 638 & 30446 & 0.217868339 & 0.41588785 & 0.086448598 & 18242 & -1.10284482 & 0 & 0 \\
\hline 41544 & 0 & 0 & 891 & 23777 & 0.203142536 & 0.413680782 & 0.169381107 & 52901 & -0.92871559 & 0 & 0 \\
\hline 41547 & 0 & 0 & 429 & 29100 & 0.2004662 & 0.530405405 & 0.091216216 & 11580 & -1.2599427 & 0 & 0 \\
\hline 41548 & 0 & 0 & 662 & 42760 & 0.181268882 & 0.460084034 & 0.098739496 & 41969 & -0.92094762 & 0 & 0 \\
\hline 41553 & 0 & 0 & 2398 & 24439 & 0.188490409 & 0.516053707 & 0.071220082 & 45626 & -0.9432139 & 0 & 0 \\
\hline 41554 & 0 & 0 & 1226 & 32515 & 0.19004894 & 0.418685121 & 0.080738178 & 49268 & -0.89498272 & 0 & 0 \\
\hline 41555 & 0 & 0 & 820 & 19130 & 0.208536585 & 0.436944938 & 0.085257549 & 0 & -1.22365494 & 0 & 0 \\
\hline 41557 & 0 & 0 & 2070 & 28666 & 0.196135266 & 0.330130405 & 0.113246397 & 54891 & -0.70059057 & 0 & 0 \\
\hline 41558 & 0 & 0 & 865 & 34161 & 0.184971098 & 0.44045677 & 0.11908646 & 43314 & -0.92192026 & 0 & 0 \\
\hline 41559 & 0 & 0 & 366 & 17646 & 0.196721311 & 0.3828125 & 0.08984375 & 20960 & -1.20930506 & 0 & 0 \\
\hline 41560 & 0 & 0 & 592 & 41422 & 0.190878378 & 0.386634845 & 0.133651551 & 6863 & -0.92913527 & 0 & 0 \\
\hline 41562 & 0 & 0 & 2939 & 27633 & 0.206532834 & 0.410079051 & 0.101778656 & 37228 & -0.76829513 & 0 & 0 \\
\hline 41563 & 0 & 0 & 406 & 24086 & 0.179802956 & 0.462328767 & 0.116438356 & 19447 & -1.17425519 & 0 & 0 \\
\hline 41564 & 0 & 0 & 1061 & 45227 & 0.201696513 & 0.370218579 & 0.133879781 & 40198 & -0.73523187 & 0 & 0 \\
\hline 41566 & 0 & 0 & 757 & 28710 & 0.199471598 & 0.525714286 & 0.04952381 & 20845 & -1.2157364 & 0 & 0 \\
\hline 41567 & 0 & 0 & 424 & 30446 & 0.212264151 & 0.386759582 & 0.097560976 & 37125 & -1.05770318 & 0 & 0 \\
\hline 41568 & 0 & 0 & 990 & 24439 & 0.201010101 & 0.592375367 & 0.098240469 & 21247 & -1.22830654 & 0 & 0 \\
\hline 41571 & 0 & 0 & 594 & 31584 & 0.171717172 & 0.329519451 & 0.107551487 & 27003 & -0.92037566 & 0 & 0 \\
\hline 41572 & 0 & 0 & 3645 & 30342 & 0.193415638 & 0.449648712 & 0.113583138 & 52664 & -0.65932933 & 0 & 0 \\
\hline 41601 & 0 & 0 & 652 & 24869 & 0.188650307 & 0.37605042 & 0.138655462 & 16785 & -1.02366629 & 0 & 0 \\
\hline 41602 & 0 & 0 & $\mathbf{5 7 6}$ & 43072 & 0.199652778 & 0.317307692 & 0.180288462 & 30164 & -0.75637097 & 0 & 0 \\
\hline 41603 & 0 & 0 & 1329 & 41170 & 0.217456734 & 0.409745293 & 0.086378738 & 16982 & -0.89549341 & 0 & 0 \\
\hline 41604 & 0 & 0 & 531 & 19303 & 0.207156309 & 0.574585635 & 0.077348066 & 14639 & -1.38332142 & 0 & 0 \\
\hline 41605 & 1 & 0 & 495 & 48267 & 0.181818182 & 0.411267606 & 0.247887324 & 59471 & -0.5473424 & 0 & 0 \\
\hline 41606 & 0 & 0 & 1068 & 19113 & 0.192883895 & 0.44966443 & 0.096644295 & 13880 & -1.13442378 & 0 & 0 \\
\hline 41607 & 0 & 0 & 336 & 29632 & 0.193452381 & 0.29535865 & 0.202531646 & 21638 & -0.8977997 & 0 & 0 \\
\hline 41612 & 0 & 0 & 38 & 19113 & 0.184210526 & 0.333333333 & 0.037037037 & 2709 & -1.35836072 & 0 & 0 \\
\hline 41615 & 0 & 0 & 771 & 41170 & 0.208819715 & 0.409774436 & 0.086466165 & 47812 & -0.89856109 & 0 & 0 \\
\hline 41616 & 0 & 0 & 848 & 23352 & 0.211084906 & 0.291808874 & 0.14334471 & 19207 & -0.93614825 & 0 & 0 \\
\hline 41619 & 0 & 0 & 723 & 21788 & 0.222683264 & 0.424489796 & 0.132653061 & 32726 & -1.09467898 & 0 & 0 \\
\hline 41621 & 0 & 0 & 149 & 19902 & 0.194630872 & 0.439252336 & 0.14953271 & 4992 & -1.28067695 & 0 & 0 \\
\hline 41622 & 0 & 0 & 145 & 28947 & 0.2 & 0.2 & 0.16 & 1682 & -0.97181267 & 0 & 0 \\
\hline 41630 & 0 & 0 & 813 & 24174 & 0.188191882 & 0.428082192 & 0.102739726 & 25160 & -1.07072206 & 0 & 0 \\
\hline 41631 & 1 & 0 & 1175 & 22392 & 0.219574468 & 0.544642857 & 0.088010204 & 29855 & -1.07640217 & 0 & 0 \\
\hline 41632 & 0 & 0 & 716 & 18163 & 0.231843575 & 0.544871795 & 0.079059829 & 13754 & -1.3576605 & 0 & 0 \\
\hline 41635 & 1 & 0 & 2693 & 16216 & 0.202005199 & 0.436227224 & 0.124330118 & 37766 & -0.77729074 & 0 & 0 \\
\hline 41636 & 0 & 0 & 831 & 29212 & 0.223826715 & 0.42300885 & 0.134513274 & 32012 & -1.00935594 & 0 & 0 \\
\hline 41640 & 0 & 0 & 1993 & 21764 & 0.204214752 & 0.446594982 & 0.097491039 & 24619 & -0.97962763 & 0 & 0 \\
\hline 41642 & 0 & 0 & 873 & 32614 & 0.205040092 & 0.407590759 & 0.158415842 & 78216 & -0.80296965 & 0 & 0 \\
\hline 41643 & 0 & 0 & 56 & 28638 & 0.178571429 & 0.4 & 0.15 & 0 & -1.20272146 & 0 & 0 \\
\hline 41645 & 1 & 0 & 1120 & 42883 & 0.207142857 & 0.252604167 & 0.158854167 & 29012 & -0.52866784 & 0 & 0 \\
\hline 41647 & 0 & 0 & 1746 & 26251 & 0.227376861 & 0.398642918 & 0.134860051 & 30773 & -0.89316707 & 0 & 0 \\
\hline 41649 & 1 & 0 & 2764 & 24869 & 0.201157742 & 0.343987823 & 0.141552511 & 42809 & -0.57279286 & 0 & 0 \\
\hline 41650 & 0 & 0 & 403 & 29212 & 0.183622829 & 0.515789474 & 0.09122807 & 10318 & -1.23411295 & 0 & 0 \\
\hline 41653 & 8 & 1 & 11210 & 31257 & 0.184834969 & 0.345663739 & 0.188543857 & 70459 & 0.898690606 & 1 & 1 \\
\hline
\end{tabular}




\begin{tabular}{|c|c|c|c|c|c|c|c|c|c|c|c|}
\hline 41655 & 0 & 0 & 1280 & 28475 & 0.221875 & 0.468677494 & 0.100928074 & 37443 & -1.0146425 & 0 & 0 \\
\hline 41659 & 0 & 0 & 436 & 48267 & 0.185779817 & 0.392282958 & 0.221864952 & 18208 & -0.77938926 & 0 & 0 \\
\hline 41660 & 0 & 0 & 696 & 19303 & 0.209770115 & 0.554621849 & 0.039915966 & 25788 & -1.34960311 & 0 & 0 \\
\hline 41663 & 0 & 0 & 274 & 41170 & 0.215328467 & 0.451086957 & 0.130434783 & 20094 & -1.07097858 & 0 & 0 \\
\hline 41666 & 0 & 0 & 909 & 29182 & 0.185918592 & 0.391502276 & 0.115326252 & 31939 & -0.94285509 & 0 & 0 \\
\hline 41667 & 0 & 0 & 906 & 17010 & 0.21192053 & 0.431340872 & 0.071082391 & 24451 & -1.18599073 & 0 & 0 \\
\hline 41669 & 0 & 0 & 553 & 14725 & 0.160940325 & 0.42014742 & 0.066339066 & 16873 & -1.22217902 & 0 & 0 \\
\hline 41701 & 8 & 2 & 17560 & 25206 & 0.193849658 & 0.388676793 & 0.150109658 & 51301 & 0.964704806 & 1 & 3 \\
\hline 41712 & 0 & 0 & 256 & 23508 & 0.18359375 & 0.404371585 & 0.158469945 & 17430 & -1.12674653 & 0 & 0 \\
\hline 41713 & 0 & 0 & 14 & 22776 & 0.214285714 & 0.111111111 & 0 & 0 & -1.21483543 & 0 & 0 \\
\hline 41714 & 0 & 0 & 572 & 28429 & 0.187062937 & 0.509852217 & 0.091133005 & 10610 & -1.20156236 & 0 & 0 \\
\hline 41719 & 0 & 0 & 1724 & 25206 & 0.186194896 & 0.382926829 & 0.156910569 & 14879 & -0.85424515 & 0 & 0 \\
\hline 41721 & 0 & 0 & 871 & 36900 & 0.206659013 & 0.390202703 & 0.113175676 & 29688 & -0.91082853 & 0 & 0 \\
\hline 41722 & 0 & 0 & 908 & 30560 & 0.183920705 & 0.391371341 & 0.115562404 & 23053 & -0.94847013 & 0 & 0 \\
\hline 41723 & 0 & 0 & 1494 & 32345 & 0.224899598 & 0.447046843 & 0.074338086 & 25332 & -0.99156592 & 0 & 0 \\
\hline 41725 & 0 & 0 & 94 & 25579 & 0.191489362 & 0.4 & 0.107692308 & 0 & -1.26951382 & 0 & 0 \\
\hline 41727 & 0 & 0 & 587 & 46983 & 0.204429302 & 0.428217822 & 0.126237624 & 11269 & -0.93479906 & 0 & 0 \\
\hline 41729 & 0 & 0 & 42 & 18918 & 0.1666666667 & 0.413793103 & 0.137931034 & 11157 & -1.28585238 & 0 & 0 \\
\hline 41731 & 0 & 0 & 923 & 18602 & 0.189599133 & 0.493883792 & 0.091743119 & 27756 & -1.17377063 & 0 & 0 \\
\hline 41735 & 0 & 0 & 220 & 31423 & 0.190909091 & 0.583333333 & 0.057692308 & 11632 & -1.37270974 & 0 & 0 \\
\hline 41739 & 0 & 0 & 175 & 30560 & 0.188571429 & 0.4 & 0.104 & 0 & -1.19155812 & 0 & 0 \\
\hline 41740 & 0 & 0 & 905 & 25579 & 0.193370166 & 0.3808 & 0.1216 & 13239 & -1.0100824 & 0 & 0 \\
\hline 41745 & 0 & 0 & 152 & 36900 & 0.203947368 & 0.398058252 & 0.106796117 & 8239 & -1.13795477 & 0 & 0 \\
\hline 41746 & 0 & 0 & 791 & 32134 & 0.209860936 & 0.565055762 & 0.065055762 & 22777 & -1.20843349 & 0 & 0 \\
\hline 41749 & 1 & 0 & 3709 & 28429 & 0.183337827 & 0.457703927 & 0.120090634 & 43596 & -0.57160032 & 0 & 0 \\
\hline 41751 & 0 & 0 & 61 & 37483 & 0.196721311 & 0.441860465 & 0.093023256 & 4104 & -1.23509023 & 0 & 0 \\
\hline 41754 & 0 & 0 & 338 & 41360 & 0.207100592 & 0.471615721 & 0.126637555 & 8534 & -1.09258392 & 0 & 0 \\
\hline 41759 & 0 & 0 & 244 & 27756 & 0.18852459 & 0.341176471 & 0.117647059 & 16556 & -1.08325379 & 0 & 0 \\
\hline 41760 & 0 & 0 & 5 & 24648 & 0.2 & 0 & 0 & 0 & -1.08807791 & 0 & 0 \\
\hline 41762 & 0 & 0 & 98 & 20369 & 0.214285714 & 0.575757576 & 0.060606061 & 4150 & -1.5528786 & 0 & 0 \\
\hline 41763 & 0 & 0 & 732 & 18602 & 0.191256831 & 0.576923077 & 0.069230769 & 17818 & -1.33588163 & 0 & 0 \\
\hline 41764 & 0 & 0 & 631 & 24680 & 0.18066561 & 0.490066225 & 0.068432671 & 11146 & -1.21995707 & 0 & 0 \\
\hline 41766 & 0 & 0 & 142 & 28429 & 0.183098592 & 0.534653465 & 0.059405941 & 8819 & -1.37576931 & 0 & 0 \\
\hline 41772 & 0 & 0 & 528 & 26004 & 0.193181818 & 0.394594595 & 0.12972973 & 4792 & -1.09890113 & 0 & 0 \\
\hline 41773 & 0 & 0 & 1403 & 24648 & 0.207412687 & 0.510010537 & 0.084299262 & 24083 & -1.10445866 & 0 & 0 \\
\hline 41774 & 0 & 0 & 2988 & 37483 & 0.179718876 & 0.422077922 & 0.109925788 & 49473 & -0.61958254 & 0 & 0 \\
\hline 41775 & 0 & 0 & 158 & 36819 & 0.189873418 & 0.419642857 & 0.107142857 & 3328 & -1.15178196 & 0 & 0 \\
\hline 41776 & 0 & 0 & 1176 & 24680 & 0.194727891 & 0.456626506 & 0.104819277 & 31779 & -1.02814836 & 0 & 0 \\
\hline 41777 & 0 & 0 & 1285 & 17789 & 0.186770428 & 0.514626219 & 0.044420368 & 17149 & -1.22064403 & 0 & 0 \\
\hline 41804 & 0 & 0 & 617 & 60925 & 0.175040519 & 0.319910515 & 0.181208054 & 27338 & -0.56860582 & 0 & 0 \\
\hline 41810 & 0 & 0 & 389 & 27218 & 0.192802057 & 0.407942238 & 0.083032491 & 18946 & -1.1502394 & 0 & 0 \\
\hline 41812 & 0 & 0 & 264 & 29880 & 0.212121212 & 0.585635359 & 0.049723757 & 11940 & -1.40770422 & 0 & 0 \\
\hline 41815 & 0 & 0 & 792 & 45381 & 0.227272727 & 0.330769231 & 0.117307692 & 33112 & -0.80260505 & 0 & 0 \\
\hline 41817 & 0 & 0 & 207 & 33128 & 0.198067633 & 0.405594406 & 0.181818182 & 13651 & -1.05822352 & 0 & 0 \\
\hline 41819 & 0 & 0 & 365 & 25346 & 0.178082192 & 0.528957529 & 0.046332046 & 12078 & -1.32887652 & 0 & 0 \\
\hline 41821 & 0 & 0 & 624 & 13034 & 0.193910256 & 0.403628118 & 0.099773243 & 15974 & -1.2113507 & 0 & 0 \\
\hline 41822 & 1 & 0 & 2614 & 27975 & 0.192425402 & 0.356126915 & 0.207877462 & 52604 & -0.46628123 & 0 & 0 \\
\hline 41824 & 0 & 0 & 868 & 28459 & 0.207373272 & 0.478333333 & 0.091666667 & 37263 & -1.0788298 & 0 & 0 \\
\hline 41825 & 0 & 0 & 608 & 30443 & 0.189144737 & 0.507009346 & 0.079439252 & 26464 & -1.1523504 & 0 & 0 \\
\hline 41826 & 0 & 0 & 779 & 15830 & 0.163029525 & 0.384353741 & 0.164965986 & 25871 & -1.00978187 & 0 & 0 \\
\hline 41828 & 0 & 0 & 833 & 32013 & 0.18967587 & 0.49137931 & 0.09137931 & 15321 & -1.09577563 & 0 & 0 \\
\hline 41831 & 0 & 0 & 708 & 35119 & 0.187853107 & 0.427165354 & 0.155511811 & 18339 & -0.94892462 & 0 & 0 \\
\hline 41832 & 0 & 0 & 454 & 19309 & 0.165198238 & 0.350724638 & 0.179710145 & 10305 & -1.03243228 & 0 & 0 \\
\hline 41833 & 0 & 0 & 362 & 25346 & 0.190607735 & 0.490196078 & 0.054901961 & 4893 & -1.31384616 & 0 & 0 \\
\hline 41834 & 0 & 0 & 741 & 27552 & 0.190283401 & 0.413793103 & 0.166666667 & 35512 & -0.94858451 & 0 & 0 \\
\hline 41835 & 0 & 0 & 692 & 23561 & 0.179190751 & 0.418699187 & 0.06504065 & 34062 & -1.09832423 & 0 & 0 \\
\hline 41836 & 0 & 0 & 688 & 27552 & 0.17877907 & 0.406570842 & 0.135523614 & 10679 & -1.02861108 & 0 & 0 \\
\hline 41837 & 0 & 0 & 1622 & 38808 & 0.18865598 & 0.359861592 & 0.169550173 & 38274 & -0.65820972 & 0 & 0 \\
\hline 41838 & 0 & 0 & 802 & 30726 & 0.198254364 & 0.468468468 & 0.104504505 & 11398 & -1.09503311 & 0 & 0 \\
\hline 41839 & 0 & 0 & 1182 & 28638 & 0.175972927 & 0.426589595 & 0.132947977 & 21474 & -0.9341533 & 0 & 0 \\
\hline 41840 & 0 & 0 & 532 & 30443 & 0.195488722 & 0.44772118 & 0.09919571 & 13833 & -1.12519903 & 0 & 0 \\
\hline
\end{tabular}




\begin{tabular}{|c|c|c|c|c|c|c|c|c|c|c|c|}
\hline 41843 & 0 & 0 & 967 & 17454 & 0.19131334 & 0.439821694 & 0.106983655 & 43433 & -1.07393825 & 0 & 0 \\
\hline 41844 & 0 & 0 & 1346 & 36698 & 0.140416048 & 0.434262948 & 0.217131474 & 38158 & -0.67628036 & 0 & 0 \\
\hline 41845 & 0 & 0 & 348 & 15830 & 0.181034483 & 0.48046875 & 0.09375 & 9804 & -1.32806225 & 0 & 0 \\
\hline 41847 & 0 & 0 & 633 & 27756 & 0.186413902 & 0.319004525 & 0.108597285 & 22607 & -0.962761 & 0 & 0 \\
\hline 41848 & 0 & 0 & 86 & 13034 & 0.197674419 & 0.409836066 & 0.06557377 & 0 & -1.44771901 & 0 & 0 \\
\hline 41849 & 0 & 0 & 185 & 30726 & 0.2 & 0.4453125 & 0.1328125 & 5497 & -1.19997411 & 0 & 0 \\
\hline 41855 & 0 & 0 & 858 & 26461 & 0.206293706 & 0.478632479 & 0.112820513 & 15538 & -1.12431333 & 0 & 0 \\
\hline 41858 & 1 & 0 & 7996 & 29880 & 0.199974987 & 0.409447415 & 0.136541889 & 44371 & -0.23543858 & 0 & 0 \\
\hline 41859 & 0 & 0 & 327 & 24249 & 0.19266055 & 0.433628319 & 0.092920354 & 8288 & -1.23112977 & 0 & $\underline{0}$ \\
\hline 41861 & 0 & 0 & 99 & 28638 & 0.171717172 & 0.452054795 & 0.136986301 & 4546 & -1.2250653 & 0 & 0 \\
\hline 41862 & 0 & 0 & 916 & 24249 & 0.189956332 & 0.45984252 & 0.092913386 & 16704 & -1.11611768 & 0 & 0 \\
\hline 42001 & 12 & 2 & 26782 & 48237 & 0.196139198 & 0.139796351 & 0.338672041 & 91707 & 2.445799045 & 2 & 2 \\
\hline 42003 & 9 & 3 & 31305 & 33950 & 0.199361124 & 0.240129479 & 0.203565241 & 72259 & 1.826255114 & 1 & 3 \\
\hline 42020 & 0 & 0 & 2204 & 31216 & 0.197368421 & 0.31809275 & 0.150881777 & 26906 & -0.67714911 & 0 & 0 \\
\hline 42021 & 0 & 0 & 1585 & 31708 & 0.195583596 & 0.313848921 & 0.121402878 & 30853 & -0.7585471 & 0 & 0 \\
\hline 42022 & 0 & 0 & 8 & 49398 & 0.125 & 0 & 0 & 8056 & -0.75585097 & 0 & 0 \\
\hline 42023 & 0 & 0 & 2525 & 31708 & 0.191683168 & 0.261331841 & 0.16340235 & 40143 & -0.5349572 & 0 & 0 \\
\hline 42024 & 0 & 0 & 1418 & 41306 & 0.197461213 & 0.21664995 & 0.161484453 & 39859 & -0.53755568 & 0 & 0 \\
\hline 42025 & 5 & 1 & 19836 & 37756 & 0.185924582 & 0.244671842 & 0.197529993 & 78417 & 1.091571267 & 1 & 1 \\
\hline 42027 & 0 & 0 & 2387 & 40665 & 0.204021785 & 0.175015088 & 0.153289077 & 43811 & -0.40180216 & 0 & 0 \\
\hline 42028 & 0 & 0 & 375 & 40344 & 0.1786666667 & 0.319852941 & 0.110294118 & 16866 & -0.90997391 & 0 & 0 \\
\hline 42029 & 0 & 0 & 6250 & 44049 & 0.18736 & 0.214766607 & 0.146319569 & 66780 & -0.05310328 & 0 & 0 \\
\hline 42031 & 1 & 0 & 3236 & 31566 & 0.191285538 & 0.381676075 & 0.105514546 & 45826 & -0.52865982 & 0 & 0 \\
\hline 42032 & 0 & 0 & 28 & 28485 & 0.214285714 & 0.315789474 & 0 & 17362 & -1.30798481 & 0 & 0 \\
\hline 42035 & 0 & 0 & 903 & 38629 & 0.214839424 & 0.208469055 & 0.146579805 & 31375 & -0.68308846 & 0 & 0 \\
\hline 42036 & 0 & 0 & 1240 & 45785 & 0.17983871 & 0.346501129 & 0.118510158 & 31013 & -0.69388525 & 0 & 0 \\
\hline 42037 & 0 & 0 & 22 & 38532 & 0.181818182 & 0.25 & 0.0625 & 2686 & -1.08846424 & 0 & 0 \\
\hline 42038 & 2 & 0 & 4846 & 38532 & 0.135988444 & 0.305080284 & 0.142932351 & 86825 & 0.04004387 & 0 & 0 \\
\hline 42039 & 0 & 0 & 1437 & 40570 & 0.219206681 & 0.285266458 & 0.140020899 & 26046 & -0.68882337 & 0 & 0 \\
\hline 42040 & 0 & 0 & 1050 & 43386 & 0.198095238 & 0.227830832 & 0.182810368 & 20314 & -0.60334137 & 0 & 0 \\
\hline 42041 & 0 & 0 & 4567 & 30824 & 0.186336764 & 0.260816201 & 0.135624425 & 39848 & -0.39905077 & 0 & 0 \\
\hline 42044 & 0 & 0 & 3343 & 38652 & 0.149566258 & 0.168486739 & 0.218408736 & 94119 & -0.07658443 & 0 & 0 \\
\hline 42045 & 0 & 0 & 1951 & 33805 & 0.157355202 & 0.243371856 & 0.15635622 & 61575 & -0.47592688 & 0 & 0 \\
\hline 42047 & 0 & 0 & 220 & 43754 & 0.168181818 & 0.308641975 & 0.135802469 & 8830 & -0.89118253 & 0 & 0 \\
\hline 42048 & 0 & 0 & 1938 & 36876 & 0.176986584 & 0.270729979 & 0.155917789 & 40425 & -0.548681 & 0 & 0 \\
\hline 42049 & 0 & 0 & 1441 & 34681 & 0.174184594 & 0.215854823 & 0.222540592 & 44050 & -0.48972659 & 0 & 0 \\
\hline 42050 & 0 & 0 & 3215 & 31786 & 0.177293935 & 0.368647717 & 0.115848407 & 41067 & -0.60869909 & 0 & 0 \\
\hline 42051 & 0 & 0 & 2881 & 39217 & 0.20617841 & 0.254288597 & 0.160948537 & 28896 & -0.47358564 & 0 & 0 \\
\hline 42053 & 0 & 0 & 5612 & 45544 & 0.204205274 & 0.179216091 & 0.193398659 & 59262 & -0.03130373 & 0 & 0 \\
\hline 42054 & 0 & 0 & 1171 & 48267 & 0.191289496 & 0.178614824 & 0.188335358 & 33318 & -0.45062716 & 0 & 0 \\
\hline 42055 & 0 & 0 & 2550 & 41504 & 0.141960784 & 0.288519637 & 0.190835851 & 76521 & -0.30023377 & 0 & 0 \\
\hline 42056 & 0 & 0 & 2114 & 29284 & 0.19205298 & 0.289806795 & 0.152564957 & 42340 & -0.63269736 & 0 & 0 \\
\hline 42058 & 1 & 0 & 2372 & 42628 & 0.203625632 & 0.182486222 & 0.150642988 & 66985 & -0.23269918 & 0 & 0 \\
\hline 42060 & 0 & 0 & 20 & 34936 & 0.2 & 0 & 0.076923077 & 5788 & -0.87811898 & 0 & 0 \\
\hline 42061 & 0 & 0 & 13 & 56702 & 0.230769231 & 0 & 0 & 0 & -0.82550907 & 0 & 0 \\
\hline 42064 & 1 & 0 & 8529 & 32074 & 0.197913003 & 0.332887701 & 0.121657754 & 48341 & -0.1177184 & 0 & 0 \\
\hline 42066 & 8 & 0 & 23828 & 37911 & 0.217517207 & 0.277332837 & 0.188737816 & 64380 & 1.441875365 & 1 & 2 \\
\hline 42069 & 0 & 0 & 1060 & 56702 & 0.214150943 & 0.167822469 & 0.19001387 & 30928 & -0.41157035 & 0 & 0 \\
\hline 42071 & 8 & 3 & 29689 & 31110 & 0.151066051 & 0.186248481 & 0.350492733 & 87320 & 1.94949939 & 1 & 2 \\
\hline 42076 & 0 & 0 & 1392 & 25529 & 0.146551724 & 0.262962963 & 0.134259259 & 50355 & -0.67220132 & 0 & 0 \\
\hline 42078 & 0 & 0 & 1881 & 33830 & 0.166400851 & 0.335483871 & 0.109677419 & 36994 & -0.69069888 & 0 & 0 \\
\hline 42079 & 0 & 0 & 1484 & 46333 & 0.208221024 & 0.267591675 & 0.134786918 & 32142 & -0.59321356 & 0 & 0 \\
\hline 42081 & 0 & 0 & 2394 & 39550 & 0.182957393 & 0.277291302 & 0.150029189 & 45638 & -0.48512768 & 0 & 0 \\
\hline 42082 & 0 & 0 & 1580 & 36883 & 0.191139241 & 0.241286863 & 0.207327971 & 55549 & -0.48739505 & 0 & 0 \\
\hline 42083 & 0 & 0 & 689 & 42993 & 0.191582003 & 0.291060291 & 0.143451143 & 15656 & -0.77367507 & 0 & 0 \\
\hline 42084 & 0 & 0 & 4 & 36685 & 0.25 & 0 & 0 & 0 & -1.04169249 & 0 & 0 \\
\hline 42085 & 0 & 0 & 692 & 31549 & 0.190751445 & 0.283975659 & 0.123732252 & 26531 & -0.86349231 & 0 & 0 \\
\hline 42086 & 0 & 0 & 3074 & 52556 & 0.20396877 & 0.216 & 0.227294118 & 77859 & -0.11337705 & 0 & 0 \\
\hline 42087 & 0 & 0 & 2561 & 35369 & 0.193674346 & 0.205540166 & 0.134072022 & 50650 & -0.4546736 & 0 & 0 \\
\hline 42088 & 0 & 0 & 2708 & 33434 & 0.213072378 & 0.241454151 & 0.124796527 & 40329 & -0.54940409 & 0 & 0 \\
\hline 42101 & 14 & 2 & 56855 & 34898 & 0.200175886 & 0.25282092 & 0.248164163 & 82007 & 3.035315237 & 2 & 1 \\
\hline
\end{tabular}




\begin{tabular}{|c|c|c|c|c|c|c|c|c|c|c|c|}
\hline 42102 & 0 & 0 & 8 & 46469 & 0.125 & 0 & 0 & 0 & -0.80044787 & 0 & 0 \\
\hline 42103 & 8 & 2 & 18637 & 71210 & 0.204646671 & 0.113226609 & 0.426484302 & 135203 & 2.160684174 & 2 & 2 \\
\hline 42104 & 13 & 0 & 30318 & 51316 & 0.199683356 & 0.111722307 & 0.418531866 & 124332 & 2.868858734 & 2 & 0 \\
\hline 42120 & 0 & 0 & 2505 & 37899 & 0.216766467 & 0.436678614 & 0.065710872 & 40426 & -0.78681492 & 0 & 0 \\
\hline 42122 & 0 & 0 & 5226 & 63888 & 0.227707616 & 0.129624235 & 0.329740752 & 74009 & 0.309069765 & 0 & 0 \\
\hline 42123 & 0 & 0 & 664 & 39261 & 0.204819277 & 0.306521739 & 0.110869565 & 55399 & -0.78597395 & 0 & 0 \\
\hline 42124 & 0 & 0 & 12 & 18157 & 0.25 & 0.375 & 0 & 0 & -1.55682816 & 0 & 0 \\
\hline 42127 & 3 & 0 & 6645 & 28865 & 0.214296464 & 0.330388693 & 0.145980565 & 52968 & -0.01194127 & 0 & 0 \\
\hline 42129 & 0 & 0 & 7180 & 33330 & 0.209888579 & 0.424568528 & 0.09177665 & 48379 & -0.42521408 & 0 & 0 \\
\hline 42130 & 0 & 0 & 202 & 55775 & 0.222772277 & 0.288888889 & 0.133333333 & 2750 & -0.85148831 & 0 & 0 \\
\hline 42133 & 0 & 0 & 1768 & 32139 & 0.208710407 & 0.350287121 & 0.113207547 & 26400 & -0.80294932 & 0 & 0 \\
\hline 42134 & 4 & 2 & 17115 & 38766 & 0.209874379 & 0.278572047 & 0.159778182 & 87593 & 0.813291498 & 0 & 2 \\
\hline 42140 & 0 & 0 & 1324 & 31713 & 0.20694864 & 0.274033149 & 0.163535912 & 46322 & -0.68499355 & 0 & 0 \\
\hline 42141 & 12 & 2 & 30429 & 36589 & 0.213743468 & 0.284519633 & 0.147498438 & 77264 & 2.044813216 & 1 & 3 \\
\hline 42151 & 0 & 0 & 628 & 15478 & 0.194267516 & 0.465909091 & 0.134090909 & 16333 & -1.21171984 & 0 & 0 \\
\hline 42153 & 0 & 0 & 380 & 23621 & 0.205263158 & 0.374045802 & 0.129770992 & 14093 & -1.12657489 & 0 & 0 \\
\hline 42154 & 0 & 0 & 719 & 34764 & 0.203059805 & 0.406060606 & 0.123232323 & 11041 & -0.99915503 & 0 & 0 \\
\hline 42156 & 0 & 0 & 177 & 39261 & 0.209039548 & 0.290322581 & 0.129032258 & 2259 & -0.99839297 & 0 & 0 \\
\hline 42157 & 0 & 0 & 414 & 18964 & 0.236714976 & 0.347985348 & 0.095238095 & 22271 & -1.18984911 & 0 & 0 \\
\hline 42159 & 0 & 0 & 1490 & 42188 & 0.206040268 & 0.224289912 & 0.212536729 & 30191 & -0.50488321 & 0 & 0 \\
\hline 42160 & 0 & 0 & 2313 & 34497 & 0.230004323 & 0.35971223 & 0.116415958 & 31925 & -0.74127993 & 0 & 0 \\
\hline 42163 & 0 & 0 & 31 & 34497 & 0.193548387 & 0.380952381 & 0.047619048 & 0 & -1.27916718 & 0 & 0 \\
\hline 42164 & 4 & 0 & 16212 & 37818 & 0.215889465 & 0.337162655 & 0.133570387 & 71379 & 0.641293705 & 0 & 1 \\
\hline 42166 & 0 & 0 & 2525 & 36159 & 0.215049505 & 0.360093077 & 0.062827225 & 36152 & -0.73689643 & 0 & 0 \\
\hline 42167 & 5 & 0 & 7571 & 28946 & 0.202879408 & 0.444928085 & 0.118092354 & 58060 & 0.144472962 & 0 & 1 \\
\hline 42170 & 0 & 0 & 1272 & 46060 & 0.202044025 & 0.211912944 & 0.27720504 & 25381 & -0.42307473 & 0 & $\underline{0}$ \\
\hline 42171 & 0 & 0 & 5885 & 46956 & 0.218181818 & 0.272083017 & 0.141736269 & 51422 & -0.18195111 & 0 & 0 \\
\hline 42202 & 0 & 0 & 1767 & 26309 & 0.204301075 & 0.325163399 & 0.126633987 & 53273 & -0.74901184 & 0 & 0 \\
\hline 42204 & 0 & 0 & 1306 & 33292 & 0.246554364 & 0.320868516 & 0.150784077 & 15352 & -0.85022389 & 0 & 0 \\
\hline 42206 & 0 & 0 & 5364 & 46544 & 0.228187919 & 0.285552408 & 0.161189802 & 61762 & -0.19917169 & 0 & 0 \\
\hline 42207 & 0 & 0 & 1249 & 31967 & 0.172938351 & 0.430283224 & 0.075163399 & 49768 & -0.89285613 & 0 & 0 \\
\hline 42210 & 1 & 0 & 4294 & 23326 & 0.193758733 & 0.376859504 & 0.070743802 & 47902 & -0.54944578 & 0 & 0 \\
\hline 42211 & 2 & 0 & 13605 & 41737 & 0.193164278 & 0.276254527 & 0.177858251 & 90988 & 0.532605809 & 0 & 0 \\
\hline 42214 & 0 & 0 & 573 & 37135 & 0.218150087 & 0.484293194 & 0.107329843 & 7780 & -1.12432701 & 0 & 0 \\
\hline 42215 & 0 & 0 & 1302 & 46257 & 0.213517665 & 0.293785311 & 0.129943503 & 16144 & -0.69120957 & 0 & 0 \\
\hline 42217 & 2 & 0 & 4511 & 33397 & 0.218133452 & 0.340871845 & 0.132415601 & 49244 & -0.25804046 & 0 & 0 \\
\hline 42220 & 0 & 0 & 6063 & 34327 & 0.232393205 & 0.36525445 & 0.104537478 & 54091 & -0.42456087 & 0 & 0 \\
\hline 42232 & 0 & 0 & 937 & 69493 & 0.240128068 & 0.168831169 & 0.225649351 & 29055 & -0.31359727 & 0 & 0 \\
\hline 42234 & 0 & 0 & 2447 & 33292 & 0.249693502 & 0.344315245 & 0.155684755 & 42870 & -0.67899708 & 0 & 0 \\
\hline 42236 & 0 & 0 & 1469 & 37163 & 0.247787611 & 0.232978723 & 0.203191489 & 35731 & -0.60689562 & 0 & 0 \\
\hline 42240 & 10 & 2 & 41538 & 37163 & 0.229380326 & 0.246561922 & 0.218513008 & 75269 & 2.206401762 & 2 & 2 \\
\hline 42254 & 0 & 0 & 90 & 37163 & 0.244444444 & 0.275862069 & 0.137931034 & 2598 & -1.07094279 & 0 & 0 \\
\hline 42256 & 1 & 0 & 5394 & 40843 & 0.21449759 & 0.364205938 & 0.090983383 & 48199 & -0.30620838 & 0 & 0 \\
\hline 42259 & 0 & 0 & 1177 & 37060 & 0.142735769 & 0.498305085 & 0.082485876 & 44897 & -0.89159134 & 0 & 0 \\
\hline 42261 & 1 & 0 & 9986 & 33330 & 0.205487683 & 0.397406004 & 0.0948703 & 56615 & -0.11473556 & 0 & 0 \\
\hline 42262 & 0 & 0 & 8633 & 29079 & 0.314143403 & 0.1171875 & 0.144325658 & 67321 & -0.10646629 & 0 & 0 \\
\hline 42265 & 0 & 0 & 1509 & 42870 & 0.194831014 & 0.244840525 & 0.181988743 & 26692 & -0.54448209 & 0 & 0 \\
\hline 42266 & 0 & 0 & 2623 & 45338 & 0.264963782 & 0.326946848 & 0.182323857 & 43276 & -0.52600837 & 0 & 0 \\
\hline 42273 & 0 & 0 & 348 & 48177 & 0.172413793 & 0.339920949 & 0.09486166 & 35659 & -0.83284223 & 0 & 0 \\
\hline 42274 & 0 & 0 & 2333 & 48400 & 0.219459923 & 0.229936306 & 0.182802548 & 46489 & -0.3715946 & 0 & 0 \\
\hline 42275 & 0 & 0 & 817 & 22860 & 0.205630355 & 0.461400359 & 0.048473968 & 15314 & -1.21600537 & 0 & 0 \\
\hline 42276 & 4 & 1 & 14404 & 31447 & 0.217717301 & 0.313463515 & 0.141418294 & 66745 & 0.532550472 & 0 & 2 \\
\hline 42280 & 0 & 0 & 632 & 40843 & 0.262658228 & 0.411167513 & 0.101522843 & 16732 & -1.0463675 & 0 & 0 \\
\hline 42285 & 0 & 0 & 449 & 33960 & 0.191536748 & 0.315457413 & 0.059936909 & 7021 & -1.03715625 & 0 & 0 \\
\hline 42286 & 0 & 0 & 1329 & 42017 & 0.257336343 & 0.316290131 & 0.20332937 & 68685 & -0.59800454 & 0 & 0 \\
\hline 42301 & 16 & 2 & 42589 & 43789 & 0.213764117 & 0.190131579 & 0.228427978 & 82674 & 3.047995046 & 2 & 2 \\
\hline 42303 & 16 & 2 & 38347 & 37185 & 0.214593058 & 0.202703744 & 0.250693268 & 89883 & 2.914622372 & 2 & 2 \\
\hline 42320 & 3 & 0 & 8793 & 35247 & 0.225747754 & 0.367749617 & 0.104439531 & 53072 & 0.06901918 & 0 & 0 \\
\hline 42321 & 0 & 0 & 176 & 40604 & 0.221590909 & 0.355932203 & 0.076271186 & 16469 & -1.08977732 & 0 & 0 \\
\hline 42322 & 0 & 0 & 1 & 28603 & 0 & 0 & 0 & 0 & -0.83101757 & 0 & 0 \\
\hline 42323 & 0 & 0 & 430 & 30271 & 0.227906977 & 0.327464789 & 0.059859155 & 41406 & -1.04956672 & 0 & 0 \\
\hline
\end{tabular}




\begin{tabular}{|c|c|c|c|c|c|c|c|c|c|c|c|}
\hline 42324 & 0 & 0 & 1256 & 36845 & 0.191878981 & 0.377085651 & 0.111234705 & 22251 & -0.84309977 & 0 & 0 \\
\hline 42325 & 0 & 0 & 1680 & 40920 & 0.204166667 & 0.30848329 & 0.111396744 & 36240 & -0.66845732 & 0 & 0 \\
\hline 42326 & 0 & 0 & 622 & 30271 & 0.226688103 & 0.319612591 & 0.065375303 & 14542 & -1.05560852 & 0 & 0 \\
\hline 42327 & 0 & 0 & 4017 & 43789 & 0.206123973 & 0.271438953 & 0.150436047 & 56088 & -0.30437433 & 0 & 0 \\
\hline 42328 & 0 & 0 & 1353 & 37541 & 0.239467849 & 0.292710706 & 0.10022779 & 42313 & -0.76333972 & 0 & 0 \\
\hline 42330 & 3 & 1 & 10786 & 34981 & 0.183664009 & 0.346267887 & 0.118473637 & 63353 & 0.273258221 & 0 & 0 \\
\hline 42332 & 0 & 0 & 17 & 23140 & 0.176470588 & 0.25 & 0.083333333 & 11293 & -1.18230333 & 0 & 0 \\
\hline 42333 & 0 & 0 & 1236 & 35247 & 0.220873786 & 0.360675513 & 0.066344994 & 15921 & -0.94126329 & 0 & 0 \\
\hline 42337 & 0 & 0 & 2297 & 26401 & 0.208532869 & 0.400253325 & 0.087397087 & 28958 & -0.86753858 & 0 & 0 \\
\hline 42338 & 0 & 0 & 89 & 41130 & 0.224719101 & 0.322033898 & 0.118644068 & 4011 & -1.07562317 & 0 & 0 \\
\hline 42339 & 0 & 0 & 783 & 36845 & 0.19412516 & 0.402504472 & 0.103756708 & 24094 & -0.94652259 & 0 & 0 \\
\hline 42343 & 0 & 0 & 1658 & 32400 & 0.197225573 & 0.341968912 & 0.107944732 & 35492 & -0.77678243 & 0 & 0 \\
\hline 42344 & 0 & 0 & 1280 & 31243 & 0.20703125 & 0.427765237 & 0.064334086 & 25028 & -1.00113868 & 0 & 0 \\
\hline 42345 & 1 & 1 & 10970 & 35151 & 0.189425706 & 0.309037529 & 0.147817207 & 64504 & 0.128253376 & 0 & 1 \\
\hline 42347 & 4 & 1 & 6242 & 37541 & 0.218840115 & 0.298411946 & 0.151694714 & 53316 & 0.183210473 & 0 & 1 \\
\hline 42348 & 0 & 0 & 4963 & 44403 & 0.224058029 & 0.234753295 & 0.122893043 & 62702 & -0.23043283 & 0 & 0 \\
\hline 42349 & 0 & 0 & 1523 & 30913 & 0.218647406 & 0.46131528 & 0.066731141 & 28334 & -1.00859689 & 0 & 0 \\
\hline 42350 & 0 & 0 & 1390 & 26242 & 0.211510791 & 0.300838574 & 0.098532495 & 47426 & -0.82435414 & 0 & 0 \\
\hline 42351 & 1 & 0 & 4220 & 43316 & 0.225592417 & 0.202621325 & 0.165781084 & 71394 & -0.08781828 & 0 & 0 \\
\hline 42352 & 0 & 0 & 1606 & 42427 & 0.212951432 & 0.283348666 & 0.150873965 & 50954 & -0.57307274 & 0 & 0 \\
\hline 42354 & 0 & 0 & 68 & 38930 & 0.220588235 & 0.444444444 & 0.066666667 & 10423 & -1.26245724 & 0 & 0 \\
\hline 42355 & 0 & 0 & 2279 & 46757 & 0.236946029 & 0.262978142 & 0.120901639 & 64174 & -0.47067628 & 0 & 0 \\
\hline 42356 & 0 & 0 & 1 & 48446 & 0 & 0 & 0 & 0 & -0.65441487 & 0 & 0 \\
\hline 42361 & 0 & 0 & 807 & 39319 & 0.215613383 & 0.35154827 & 0.127504554 & 10609 & -0.90124668 & 0 & 0 \\
\hline 42366 & 0 & 0 & 6196 & 57676 & 0.233699161 & 0.143892081 & 0.195103672 & 5768 & -0.00785875 & 0 & 0 \\
\hline 42367 & 0 & 0 & 211 & 20727 & 0.180094787 & 0.450980392 & 0.052287582 & 83878 & -1.16930825 & 0 & 0 \\
\hline 42368 & 0 & 0 & 1071 & 47876 & 0.225023343 & 0.286115007 & 0.105189341 & 47371 & -0.67033487 & 0 & 0 \\
\hline 42369 & 0 & 0 & 84 & 37541 & 0.226190476 & 0.303571429 & 0.107142857 & 12949 & -1.08586412 & 0 & 0 \\
\hline 42370 & 0 & 0 & 2 & 30913 & 0 & 0 & 0 & 0 & -0.80644727 & 0 & 0 \\
\hline 42371 & 0 & 0 & 1220 & 36508 & 0.195081967 & 0.366164542 & 0.114716107 & 18368 & -0.8493404 & 0 & 0 \\
\hline 42372 & 0 & 0 & 1653 & 33163 & 0.199637024 & 0.272493573 & 0.150814053 & 40122 & -0.64874778 & 0 & 0 \\
\hline 42374 & 0 & 0 & 166 & 34878 & 0.204819277 & 0.373913043 & 0.069565217 & 8337 & -1.16828333 & 0 & 0 \\
\hline 42376 & 0 & 0 & 5460 & 55319 & 0.219413919 & 0.194360799 & 0.193265809 & 64505 & 0.025218033 & 0 & 0 \\
\hline 42378 & 0 & 0 & 3596 & 40624 & 0.238598443 & 0.233968804 & 0.149913345 & 53301 & -0.37412844 & 0 & 0 \\
\hline 42404 & 0 & 0 & 3072 & 42796 & 0.210611979 & 0.288689068 & 0.083293895 & 39381 & -0.52349863 & 0 & 0 \\
\hline 42406 & 0 & 0 & 3466 & 41269 & 0.215810733 & 0.235824742 & 0.155498282 & 51466 & -0.35230592 & 0 & 0 \\
\hline 42408 & 1 & 0 & 6302 & 32161 & 0.211202793 & 0.347351301 & 0.084572491 & 42518 & -0.32573042 & 0 & 0 \\
\hline 42409 & 0 & 0 & 2569 & 40354 & 0.170494356 & 0.279552716 & 0.084132055 & 50001 & -0.51002108 & 0 & 0 \\
\hline 42410 & 1 & 0 & 279 & 23509 & 0.229390681 & 0.37704918 & 0.049180328 & 26282 & -1.13560473 & 0 & 0 \\
\hline 42411 & 0 & 0 & 1946 & 32808 & 0.172661871 & 0.284002819 & 0.140944327 & 31819 & -0.62788278 & 0 & 0 \\
\hline 42413 & 0 & 0 & 2931 & 54324 & 0.201296486 & 0.193389245 & 0.226936359 & 45088 & -0.16094367 & 0 & 0 \\
\hline 42420 & 12 & 1 & 38084 & 38299 & 0.208171411 & 0.216473194 & 0.216855048 & 83216 & 2.422163564 & 2 & 1 \\
\hline 42431 & 9 & 1 & 27918 & 40040 & 0.204455907 & 0.268949795 & 0.171597327 & 64693 & 1.699075256 & 1 & 1 \\
\hline 42436 & 0 & 0 & 1174 & 58499 & 0.200170358 & 0.210526316 & 0.211750306 & 36045 & -0.36886458 & 0 & 0 \\
\hline 42437 & 4 & 0 & 8935 & 50365 & 0.193284835 & 0.223813355 & 0.155913113 & 60108 & 0.570197947 & 0 & 1 \\
\hline 42440 & 0 & 0 & 83 & 31705 & 0.192771084 & 0.338983051 & 0.118644068 & 30040 & -1.08189079 & 0 & 0 \\
\hline 42441 & 0 & 0 & 1659 & 43844 & 0.198915009 & 0.270199826 & 0.145091225 & 33297 & -0.57180415 & 0 & 0 \\
\hline 42442 & 0 & 0 & 4334 & 31773 & 0.213659437 & 0.36868858 & 0.080989495 & 45147 & -0.59135763 & 0 & 0 \\
\hline 42445 & 3 & 0 & 11844 & 36515 & 0.192333671 & 0.269239962 & 0.13706979 & 48530 & 0.385877827 & 0 & 0 \\
\hline 42450 & 2 & 0 & 3761 & 27600 & 0.211645839 & 0.298989114 & 0.127527216 & 36796 & -0.35180657 & 0 & 0 \\
\hline 42451 & 0 & 0 & 1499 & 59752 & 0.204136091 & 0.206796117 & 0.194174757 & 23063 & -0.36451942 & 0 & 0 \\
\hline 42452 & 0 & 0 & 2418 & 59050 & 0.207609595 & 0.213851762 & 0.204738761 & 52753 & -0.2006807 & 0 & 0 \\
\hline 42453 & 0 & 0 & 499 & 32370 & 0.184368737 & 0.418994413 & 0.047486034 & 14027 & -1.12980732 & 0 & 0 \\
\hline 42455 & 0 & 0 & 3388 & 36476 & 0.233471074 & 0.281557744 & 0.161145927 & 54462 & -0.45348903 & 0 & 0 \\
\hline 42456 & 0 & 0 & 1592 & 44436 & 0.209798995 & 0.220494053 & 0.142726441 & 29939 & -0.54929288 & 0 & 0 \\
\hline 42458 & 0 & 0 & 898 & 59752 & 0.208240535 & 0.220588235 & 0.199346405 & 24543 & -0.4584467 & 0 & 0 \\
\hline 42459 & 1 & 0 & 4300 & 30417 & 0.203488372 & 0.25338295 & 0.154262517 & 43616 & -0.29655228 & 0 & 0 \\
\hline 42461 & 0 & 0 & 1122 & 30047 & 0.215686275 & 0.298527443 & 0.089692102 & 47072 & -0.84019615 & 0 & 0 \\
\hline 42462 & 0 & 0 & 911 & 40045 & 0.215148189 & 0.240650407 & 0.128455285 & 37742 & -0.70584713 & 0 & 0 \\
\hline 42463 & 0 & 0 & 66 & 45886 & 0.196969697 & 0.282608696 & 0.043478261 & 3633 & -1.05761716 & 0 & 0 \\
\hline 42464 & 0 & 0 & 2221 & 42829 & 0.211166141 & 0.345191041 & 0.085638999 & 41237 & -0.65230796 & 0 & 0 \\
\hline
\end{tabular}




\begin{tabular}{|c|c|c|c|c|c|c|c|c|c|c|c|}
\hline 42501 & 10 & 2 & 19285 & 30455 & 0.202385274 & 0.336522771 & 0.16451565 & 62200 & 1.373346604 & 1 & 1 \\
\hline 42503 & 6 & 1 & 20705 & 42239 & 0.201110843 & 0.279481132 & 0.189511654 & 81654 & 1.21768055 & 1 & 1 \\
\hline 42516 & 0 & 0 & 485 & 31725 & 0.216494845 & 0.498480243 & 0.045592705 & 8305 & -1.26862075 & 0 & 0 \\
\hline 42518 & 0 & 0 & 2934 & 29701 & 0.197682345 & 0.331222601 & 0.138821237 & 74704 & -0.5369882 & 0 & 0 \\
\hline 42519 & 0 & 0 & 3175 & 28188 & 0.183307087 & 0.502426114 & 0.084252316 & 53338 & -0.78722552 & 0 & 0 \\
\hline 42528 & 0 & 0 & 1788 & 29508 & 0.211409396 & 0.456718879 & 0.115416323 & 20917 & -0.94086697 & 0 & 0 \\
\hline 42533 & 0 & 0 & 510 & 30455 & 0.231372549 & 0.269230769 & 0.153846154 & 33816 & -0.89302751 & 0 & 0 \\
\hline 42539 & 2 & 0 & 9370 & 25467 & 0.200320171 & 0.411809699 & 0.101881597 & 46321 & -0.12957877 & 0 & 0 \\
\hline 42541 & 0 & 0 & 637 & 20683 & 0.202511774 & 0.314479638 & 0.126696833 & 26217 & -1.0114325 & 0 & 0 \\
\hline 42544 & 1 & 0 & 5806 & 30123 & 0.173957975 & 0.346153846 & 0.146575985 & 68598 & -0.20280171 & 0 & 0 \\
\hline 42553 & 0 & 0 & 6392 & 31924 & 0.216051314 & 0.357734807 & 0.13213628 & 42851 & -0.3952643 & 0 & 0 \\
\hline 42565 & 0 & 0 & 840 & 28821 & 0.264285714 & 0.595375723 & 0.080924855 & 11869 & -1.33058222 & 0 & 0 \\
\hline 42566 & 0 & 0 & 635 & 31725 & 0.209448819 & 0.435483871 & 0.046082949 & 9827 & -1.16437079 & 0 & 0 \\
\hline 42567 & 0 & 0 & 6512 & 30506 & 0.2129914 & 0.398108534 & 0.081513173 & 46735 & -0.48227868 & 0 & 0 \\
\hline 42602 & 3 & 0 & 10000 & 25463 & 0.2147 & 0.465439791 & 0.11375163 & 52555 & -0.03084154 & 0 & 0 \\
\hline 42603 & 0 & 0 & 158 & 21347 & 0.208860759 & 0.444444444 & 0.074074074 & 11382 & -1.35312485 & 0 & 0 \\
\hline 42629 & 0 & 0 & 4936 & 24037 & 0.196515397 & 0.396926645 & 0.161206147 & 65471 & -0.49102046 & 0 & 0 \\
\hline 42631 & 0 & 0 & 12 & 25746 & 0.25 & 0.125 & 0 & 32790 & -1.17092571 & 0 & 0 \\
\hline 42633 & 5 & 1 & 20181 & 25433 & 0.199445023 & 0.428212491 & 0.105384063 & 55113 & 0.646000556 & 0 & 1 \\
\hline 42634 & 0 & 0 & 1758 & 18806 & 0.232650739 & 0.509615385 & 0.076048951 & 19230 & -1.1623795 & 0 & 0 \\
\hline 42635 & 0 & 0 & 2956 & 24663 & 0.158322057 & 0.508241758 & 0.150641026 & 41623 & -0.76913449 & 0 & 0 \\
\hline 42638 & 0 & 0 & 335 & 24488 & 0.217910448 & 0.45 & 0.095454545 & 20268 & -1.24200158 & 0 & 0 \\
\hline 42642 & 0 & 0 & 12542 & 30027 & 0.200047839 & 0.376869506 & 0.141682841 & 59709 & -0.05261422 & 0 & 0 \\
\hline 42647 & 0 & 0 & 3434 & 19025 & 0.208211998 & 0.487722269 & 0.116426757 & 34935 & -0.86921607 & 0 & 0 \\
\hline 42649 & 0 & 0 & 3373 & 20597 & 0.221761044 & 0.530501582 & 0.078174424 & 28163 & -0.97476412 & 0 & 0 \\
\hline 42653 & 1 & 0 & 4969 & 25746 & 0.213725096 & 0.414341434 & 0.136813681 & 34592 & -0.49857304 & 0 & 0 \\
\hline 42701 & 17 & 3 & 50357 & 48691 & 0.225092837 & 0.17582483 & 0.254633624 & 104015 & 3.45390538 & 2 & 3 \\
\hline 42712 & 0 & 0 & 1904 & 43344 & 0.214285714 & 0.367000771 & 0.115651503 & 36557 & -0.68460215 & 0 & 0 \\
\hline 42713 & 0 & 0 & 1404 & 30055 & 0.215099715 & 0.453488372 & 0.076109937 & 37617 & -0.98802145 & 0 & 0 \\
\hline 42715 & 0 & 0 & 312 & 24011 & 0.205128205 & 0.45971564 & 0.123222749 & 13259 & -1.23294065 & 0 & 0 \\
\hline 42716 & 0 & 0 & 1586 & 37235 & 0.21185372 & 0.335507922 & 0.107176142 & 37212 & -0.75010943 & 0 & 0 \\
\hline 42717 & 1 & 0 & 6822 & 27764 & 0.200967458 & 0.444863732 & 0.103563941 & 52458 & -0.37310874 & 0 & 0 \\
\hline 42718 & 3 & 1 & 24781 & 36126 & 0.19595658 & 0.313605717 & 0.178470581 & 72311 & 0.905213904 & 1 & 2 \\
\hline 42721 & 1 & 0 & 4243 & 32466 & 0.218006128 & 0.435178697 & 0.097407148 & 44127 & -0.53666562 & 0 & 0 \\
\hline 42722 & 0 & 0 & 763 & 35166 & 0.217562254 & 0.397260274 & 0.109589041 & 29201 & -0.96918262 & 0 & 0 \\
\hline 42724 & 0 & 0 & 4159 & 39033 & 0.217840827 & 0.262784091 & 0.146661932 & 49272 & -0.36100686 & 0 & 0 \\
\hline 42726 & 0 & 0 & 4962 & 30069 & 0.207779121 & 0.349607672 & 0.095030514 & 56152 & -0.49593806 & 0 & 0 \\
\hline 42728 & 3 & 1 & 16285 & 29222 & 0.193552349 & 0.38785291 & 0.157110491 & 60926 & 0.436419547 & 0 & 1 \\
\hline 42729 & 0 & 0 & 1826 & 28504 & 0.234939759 & 0.435414885 & 0.053892216 & 28497 & -1.00157562 & 0 & 0 \\
\hline 42731 & 0 & 0 & 182 & 17289 & 0.225274725 & 0.401639344 & 0.090163934 & 6635 & -1.35138366 & 0 & 0 \\
\hline 42732 & 0 & 0 & 2252 & 36950 & 0.218916519 & 0.310979619 & 0.132807364 & 54118 & -0.59648869 & 0 & 0 \\
\hline 42733 & 0 & 0 & 1376 & 25581 & 0.208575581 & 0.486573577 & 0.083780881 & 37444 & -1.04807835 & 0 & 0 \\
\hline 42740 & 0 & 0 & 2074 & 59920 & 0.228061716 & 0.242159008 & 0.207877462 & 54901 & -0.27118558 & 0 & 0 \\
\hline 42741 & 0 & 0 & 380 & 36618 & 0.197368421 & 0.441947566 & 0.08988764 & 17475 & -1.10313448 & 0 & 0 \\
\hline 42743 & 3 & 0 & 8714 & 37836 & 0.195776911 & 0.386922321 & 0.123238283 & 51323 & 0.120747776 & 0 & 0 \\
\hline 42746 & 0 & 0 & 1763 & 35942 & 0.216108905 & 0.44783715 & 0.076335878 & 38308 & -0.88572708 & 0 & 0 \\
\hline 42748 & 4 & 0 & 9071 & 38567 & 0.211222577 & 0.263746959 & 0.182481752 & 69199 & 0.462082655 & 0 & 0 \\
\hline 42749 & 1 & 0 & 5602 & 24524 & 0.216172795 & 0.389122438 & 0.122700998 & 54919 & -0.41417959 & 0 & 0 \\
\hline 42753 & 0 & 0 & 635 & 31167 & 0.22992126 & 0.464547677 & 0.100244499 & 17384 & -1.14539245 & 0 & 0 \\
\hline 42754 & 0 & 0 & 14826 & 30956 & 0.206259274 & 0.369179163 & 0.127170481 & 59714 & 0.034760316 & 0 & 0 \\
\hline 42757 & 0 & 0 & 2842 & 38303 & 0.203377903 & 0.349949135 & 0.132756867 & 51158 & -0.55431001 & 0 & 0 \\
\hline 42758 & 0 & 0 & 20 & 39466 & 0.2 & 0.153846154 & 0 & 0 & -1.08404693 & 0 & 0 \\
\hline 42762 & 0 & 0 & 673 & 30045 & 0.224368499 & 0.439732143 & 0.131696429 & 12095 & -1.09562814 & 0 & 0 \\
\hline 42764 & 0 & 0 & 509 & 33989 & 0.21021611 & 0.392550143 & 0.074498567 & 10582 & -1.09638947 & 0 & 0 \\
\hline 42765 & 0 & 0 & 5814 & 27535 & 0.21620227 & 0.433787606 & 0.096682952 & 42908 & -0.58256482 & 0 & 0 \\
\hline 42776 & 0 & 0 & 2887 & 36530 & 0.231035677 & 0.33492569 & 0.128980892 & 39522 & -0.6146135 & 0 & 0 \\
\hline 42782 & 0 & 0 & 1091 & 39781 & 0.207149404 & 0.3708166 & 0.077643909 & 20331 & -0.89291539 & 0 & 0 \\
\hline 42784 & 0 & 0 & 2325 & 36919 & 0.232688172 & 0.372937294 & 0.120792079 & 33798 & -0.725453 & 0 & 0 \\
\hline 42788 & 0 & 0 & 299 & 45651 & 0.183946488 & 0.221698113 & 0.155660377 & 23896 & -0.72823623 & 0 & 0 \\
\hline
\end{tabular}




\section{CURRICULUM VITAE}

\section{Wes Cardall, DMD}

EDUCATION

AWARDS \& HONORS

PROFESSIONAL EXPERIENCE

RESEARCH

PROFESSIONAL ACTIVITIES
2010-2012 University of Louisville, M.S. in Oral Biology and Certificate in Orthodontics

2005-2007 Arizona School of Dentistry \& Oral Health (ASDOH), D.M.D. 2006-2007 University of North Carolina at Chapel Hill, Distance Learning Program, Certificate in Core Public Health Concepts

2003-2005 University of California, Los Angeles (UCLA), School of Dentistry 1997-2003 Brigham Young University (BYU), B.S. Zoology

Inducted into Omicron Kappa Upsilon, the national dental honor society Graduated Summa Cum Laude from the Arizona School of Dentistry \& Oral Health with 4.0 GPA

UCLA Affiliates Scholarship (2005)

UCLA Dean's Scholarship (2003)

California Dental Association Foundation Scholarship (2004)

American Academy of Dental Research (AADR) Bloc Travel Grant for poster presentation at IADR Australia (2006)

Graduated Summa Cum Laude from BYU with 4.0 GPA

Speaker at 2003 Convocation of BYU College of Biology \& Agriculture Winner of 2004 UCLA School of Dentistry talent show

2008-2010: Associate at Monarch Dental in American Fork, UT (General Dentistry)

- Lead dental team to set new production records in a formerly struggling corporate dental office

2007-2008: Associate at Cougar Dental in Provo, UT

- Helped grow practice and increase revenues as associate dentist

Masters Thesis: "Using A Statistical Model to Locate Potential Orthodontic Practice Sites in Kentucky"

Published in May 2008 Journal of Dental Education (see Cardall et al, 'Dental Education from the Students' Perspective: Curriculum and Climate")

Poster presentation at the IADR Australia 2006

Poster presentation at the CDA Spring 2006 Scientific Session in Anaheim

Founder and President of Orthodontics Study Club at ASDOH

Organized Give Kids a Smile! Day 2006 at ASDOH as part of the Planning Committee

Founded and co-orchestrated the Dental Student Morale Survey Project at six U.S. dental schools 
PERSONAL

INTERESTS \&

HOBBIES
Spending time with wife, Lindsey, and traveling to new places Winter surfing at the Huntington Beach Pier. Skiing in Park City, UT.

Basketball, tennis, wakeboarding, racquetball, swimming, and inline skating. Replicating popular songs on the piano and keyboard

Studying history and making authentic Swiss Fondue-and speaking French 